This manuscript has been submitted for publication in Water Resources Research. Please note that, despite having undergone peer review, the manuscript has yet to be formally accepted for publication. Subsequent versions of this manuscript may have slightly different content. If accepted, the final version of this manuscript will be available via the 'Peer-reviewed Publication DOl' link on the right-hand side of this webpage.

Please feel free to contact any of the authors; we welcome feedback. 


\title{
Effects of turbulent hyporheic mixing on reach-scale transport
}

\author{
K. R. Roche ${ }^{1,2 \dagger}$, A. Li ${ }^{1}$, D. Bolster ${ }^{2}$, G. J. Wagner ${ }^{3}$, A. I. Packman ${ }^{1}$ \\ ${ }^{1}$ Department of Civil and Environmental Engineering, Northwestern University, Evanston, \\ Illinois, USA. \\ ${ }^{2}$ Department of Civil \& Environmental Engineering \& Earth Sciences, University of Notre \\ Dame, Notre Dame, IN. \\ ${ }^{3}$ Department of Mechanical Engineering, Northwestern University, Evanston, Illinois, USA. \\ Corresponding author: Kevin Roche (kroche2@nd.edu) \\ $\dagger$ Current affiliation: Department of Civil \& Environmental Engineering \& Earth Sciences, \\ University of Notre Dame, Notre Dame, IN
}

\section{Key Points:}

- We simulated local and reach-scale solute transport for streams with a coarse-sediment hyporheic zone.

- Enhanced mixing below the sediment-water interface results in exponential tailing of breakthrough curves at intermediate times.

- High hyporheic velocities cause BTCs to deviate from current transport modeling theory. 


\begin{abstract}
Turbulence causes rapid mixing of solutes and fine particles between open channel flow and coarse-grained streambeds. Turbulent mixing is known to control hyporheic exchange fluxes and the distribution of vertical mixing rates in the streambed, but it is unclear how turbulent mixing ultimately influences mass transport at the reach scale. We used a particle-tracking model to simulate local- and reach-scale solute transport for a stream with coarse-grained sediments. Simulations were first used to determine profiles of vertical mixing rates that best described solute concentration profiles measured within a coarse granular bed in flume experiments. These vertical mixing profiles were then used to simulate a pulse solute injection to show the effects of turbulent hyporheic exchange on reach-scale solute transport. Experimentally measured concentrations were best described by simulations with a non-monotonic mixing profile, with highest mixing at the sediment-water interface and exponential decay into the bed. Reach-scale simulations show that this enhanced interfacial mixing couples in-stream and hyporheic solute transport. Coupling produces an interval of exponential decay in breakthrough curves and delays the onset of power-law tailing. High streamwise velocities in the hyporheic zone reduced mass recovery in the water column and caused breakthrough curves to exhibit steeper power-law slopes than predictions from mobile-immobile modeling theory. These results demonstrate that transport models must consider the spatial variability of streamwise velocity and vertical mixing for both the stream and the hyporheic zone, and new analytical theory is needed to describe reach-scale transport when high streamwise velocities are present in the hyporheic zone.
\end{abstract}

\title{
1 Introduction
}

Transport and transformation in the hyporheic zone are closely linked to the structure of stream sediments and to streamflow. Sediment properties such as grain size and surface chemistry influence habitat for microbial biofilms, which are a primary driver of subsurface reactions, and hyporheic residence times (Boulton et al., 1998; Battin et al., 2007; Aubeneau et al., 2016; Battin et al., 2016). Streambed topography and permeability interact with stream and groundwater flow to set the rate and timing of solute transport in the hyporheic zone.

Distributions of residence timescales and reaction timescales exerts primary control over integrated transformation rates in river networks (Zarnetske et al., 2011; Harvey et al., 2013). Thus, an accurate, physically-based description of hyporheic exchange rates and residence time distributions is needed to make generalized predictions of solute retention and transformation in streams and rivers.

Considerable research over the last 30 years has shown that hyporheic exchange is generally controlled by advective porewater flows induced by stream features such as dunes, bars, and meanders (Boano et al., 2014). However, nearly all available models consider the stream flow to be fully turbulent but hyporheic flows to be linear-laminar (i.e., Stokes flow, $R e<1$ ), and all models of advective hyporheic exchange (pumping) apply Darcy flow assumptions within the subsurface (Cardenas \& Wilson, 2007; Marion, Packman, et al., 2008; Karwan \& Saiers, 2012). A small number of studies have shown that hyporheic exchange is also induced by turbulence that propagates across the SWI (Richardson \& Parr, 1988; Nagaoka \& Ohgaki, 1990; Packman et al., 2004; Roche et al., 2018). Despite some progress integrating this information into models for upscaled hyporheic exchange and associated solute transport (Nagaoka \& Ohgaki, 1990; Higashino et al., 2009; Boano et al., 2011), full integration has remained a challenge due to an incomplete understanding of turbulent interfacial momentum 
transport. Sediment permeability and in-stream turbulent energy together control the extent to which turbulent eddies propagate across the SWI (Breugem et al., 2006; Manes et al., 2012). Surface and subsurface flows become increasingly coupled at high flowrates, particularly for flows over high-permeability sediment beds (Manes et al., 2011). Interfacial momentum coupling modifies the flow structure across the surface-subsurface continuum by increasing subsurface velocities and amplifying turbulent shear and vertical stresses near the SWI (Voermans et al., 2017). The resulting interfacial exchange rates can increase by orders of magnitude beyond advective pumping (O'Connor \& Harvey, 2008; Grant, Gomez-Velez, et al., 2018). Turbulent energy diminishes exponentially with depth in the streambed, typically limiting the thickness of the turbulent interfacial layer to the order of several grain diameters (Vollmer et al., 2002; Breugem et al., 2006; Manes et al., 2009).

Such processes are known to fundamentally violate assumptions of current upscaled transport models that are widely used in rivers, including both classical models (e.g., Transient Storage Model) and more recent models based on stochastic transport theory (e.g., ContinuousTime Random Walk, Time-Fractional Advection-Dispersion Equations, Multirate Mass Transfer) (Haggerty et al., 2002; Schumer et al., 2003; Boano et al., 2007; Marion, Zaramella, et al., 2008; Kelly et al., 2017). Present applications of these models assume that streamwise velocities are much larger than streamwise hyporheic velocities, which allows mass residing in the hyporheic zone to be considered immobile (Boano et al., 2014). However, the combination of rapid interfacial transport and high porewater velocities in the turbulent portion of the hyporheic zone indicates that surface and surbsurface flows are fully hydrodynamically coupled (Manes et al., 2009; Blois et al., 2012; Blois et al., 2013), and downstream transport within the hyporheic zone occurs at velocities on the same order as those of the stream. This violates the assumption of separation of in-stream and hyporheic velocities (Boano et al., 2007). It is presently unclear how turbulent hyporheic exchange impacts overall mass retention at the scale of stream reaches, given that the turbulent portion of the hyporheic zone is often a small fraction of the overall streambed depth. Assessment of these processes from integrated measurements of solute transport (i.e., breakthrough curves) is further confounded by the presence of additional retention mechanisms active at similar timescales, such as slow in-stream velocities in the benthic boundary layer, velocity variations around cobbles and other obstructions, and lateral exchange with side pools (Uijttewaal et al., 2001; Ensign \& Doyle, 2005; Gooseff et al., 2005; BottacinBusolin et al., 2009; Briggs et al., 2009; Orr et al., 2009; Jackson et al., 2013).

Recently, controlled experimental investigations using new in situ measurement approaches have provided direct observations of turbulent porewater flow and associated interfacial solute transport (Blois et al., 2012; Roche et al., 2018). These studies have shown that elevated shear stresses below the SWI are directly linked to enhanced mass dispersivity. New theoretical and modeling approaches are needed to link vertical profiles of enhanced mixing to integrated observations of reach scale transport that are measured in the field. To this end, we used a process-based particle tracking model to simulate mass transport in a stream with a coarse sediment bed. We parameterized the model directly by using profiles of streamwise velocity observed in Roche et al. (2018). We used concentration measurements from steady-state solute injection experiments, observed in the same study, to identify profiles of vertical dispersivity in the stream and hyporheic zone. These profiles were then used to simulate a pulse tracer experiment in a stream reach. Upscaled results were interpreted in terms of water column breakthrough curves (BTCs) and residence time distributions for mass in the hyporheic zone. 


\section{Materials and Methods}

We used a random-walk particle-tracking model to simulate downstream transport at laboratory flume and river reach scales. The 2D model discretizes tracer into a number of virtual mass particles, $N_{p}$, whose ensemble motion represents the evolution of a tracer plume. Particle motion at each time step is specified by a 2D Langevin equation (Allen \& Tildesley, 1987; Delay et al., 2005):

$$
\begin{gathered}
x(t+\Delta t)=x(t)+u_{x}(\mathrm{z}) \Delta t \\
z(t+\Delta t)=z(t)+\frac{\partial K_{z}(z)}{\partial z} \Delta t+\xi \sqrt{2 K_{z}(\mathrm{z}) \Delta t}
\end{gathered}
$$

where $x(t)$ is downstream position at time $t, z$ is vertical position, and $\Delta t$ is a unit time step; $u_{x}(\mathrm{z})$ and $K_{z}(\mathrm{z})$ represent vertically-varying fields of longitudinal velocity and vertical mixing rate, respectively; and $\xi$ is an independent random variable sampled from the standard normal distribution. Equation (1) provides a consistent framework for simulating the ensemble motion of solute mass subject to co-varying velocities and mixing intensities (Li et al., 2017). The vertical mixing profile $K_{z}(\mathrm{z})$ is assumed to be continuous and smoothly varying in z. Under the limit of $\Delta t \rightarrow 0, N_{p} \rightarrow \infty$, the asymptotic outcome of Equation (1) is the 2D advection-dispersion equation (ADE) (Risken, 1996):

$$
\frac{\partial C}{\partial t}+u_{x} \frac{\partial C}{\partial x}=\frac{\partial}{\partial z}\left(K_{z} \frac{\partial C}{\partial z}\right) .
$$

\subsection{Numerical model formulation}

We simulated transport in a stream flowing over and through a coarse-grained streambed, with the entire surface and subsurface domain considered as a single flow continuum. The sediment water interface (SWI) is defined as the top of the uppermost layer of beads. The influence of turbulence and stream sediments on motion is captured by the vertical variability of $u_{x}(\mathrm{z})$ and $K_{z}(\mathrm{z})$ (Figure 1). Velocities were simulated at three different flow conditions, which are reported in Table 1 . Streamwise velocity profiles $u_{x}(\mathrm{z})$ at each flow condition were taken directly from recent flume experiments with a water column height $H=0.123 \mathrm{~m}$ and a bed that consisted of 0.04-m spherical beads in a simple cubic packing to a depth of $d_{b}=0.224 \mathrm{~m}$ below the SWI (Roche et al., 2018). Water column velocities are based on the spatial average of velocity profiles made at different areal locations in the flume (using the method from Nikora et al. (2001)), and they vary slightly from velocities in Roche et al. (2018), which were based on a single velocity profile. Subsurface velocities were based on the median travel time measured from pulse injections in the streambed. At each flow condition, $u_{x}(\mathrm{z})$ approached a uniform porewater velocity $u_{p}$ deep in the streambed. Discharge, $Q$, was measured for the entire flume

and includes subsurface and subsurface flow. Reynolds numbers are calculated as $R e=H \bar{U}_{s} / \nu$, where $\bar{U}_{S}$ is mean water column velocity, and $v=10^{-6} \mathrm{~m}^{2} / \mathrm{s}$ is the kinematic viscosity.

Vertical mixing profiles $K_{z}(\mathrm{z})$ also span the surface-subsurface continuum. Vertical mixing profiles in the water column were determined from experimental observations by assuming $K_{z}(\mathrm{z})$ was equal to the local eddy diffusivity of momentum, $\gamma_{T}(z)$ (Tennekes \& Lumley, 1972). Eddy diffusivities were calculated from profiles of Reynolds-decomposed velocities according to (Tennekes \& Lumley, 1972; Fischer et al., 1979): 


$$
\gamma_{T}(z)=\frac{-\overline{u_{\text {exp }}^{\prime} w_{\text {exp }}^{\prime}}}{\partial u_{x} / \partial z}
$$

where $u_{\text {exp }}(z)$ and $w_{\text {exp }}$ are the streamwise and vertical components of the experimentally measured velocity time series, respectively, at elevation $z$. Primes denote fluctuations about the mean velocity (e.g., $u_{\text {exp }}^{\prime}=u_{\text {exp }}-\bar{u}_{\text {exp }}$ ); and overbars denote temporal averaging.

Mixing rates near the SWI were determined by fitting concentrations from simulations to concentrations measured experimentally from continuous, steady-state streambed injections (Roche et al., 2018). The minimum vertical mixing rate in the streambed was assumed to be governed by mechanical dispersion in the porous medium (Bear, 1979). The associated dispersion coefficient, $K_{p}$, was based upon the mechanical dispersion rate measured in experiments, $K_{p, \exp }$. Values of $K_{p, \exp }$ were estimated by fitting the 1-D advection-dispersion equation to subsurface solute injections (Roche et al., 2018). Due to experimental constraints, estimates of $K_{p, \exp }$ were biased by enhanced interfacial mixing. We therefore treated $K_{p}$ as a free parameter, where $K_{p} \in\left(0, K_{p, \exp }\right)$.

Note that this model explicitly resolves longitudinal dispersion at the scale of the streamsubsurface continuum as an outcome of Equations (2), so local longitudinal diffusion in the water column was omitted. Longitudinal dispersion in the subsurface was assumed to be insignificant relative to downstream advection, which is a valid assumption for the advection dominated conditions considered here (Fischer et al., 1979).

\subsection{Evaluation of vertical mixing profiles}

We assessed two different hypothesized profiles for $K_{z}$ in the hyporheic zone (Figure 1). First, we hypothesized that the shape of $K_{z}(z<0)$ follows the shape of hyporheic velocity profiles $u_{z}(z<0)$ observed in high-permeability streambeds, which generally show exponential decay with depth (Ruff \& Gelhar, 1972; Zagni \& Smith, 1976; Mendoza \& Zhou, 1992). For this model, we assume that $K_{z}$ decays exponentially from the eddy diffusivity at the SWI, $K_{z}(0)$, to the minimum value of $K_{p}$ at depth:

$$
K_{z}(z<0)=K_{p}+\left(K_{z}(0)-K_{p}\right) e^{\alpha z}
$$

where $\alpha$ is the rate of exponential decay. Hereafter, we refer to this simulation case as "monotonic decrease."

Second, we hypothesized that mixing is enhanced by turbulence at the SWI. This hypothesized shape is consistent with profiles of turbulent stresses measured in highpermeability streambeds (Breugem et al., 2006; Manes et al., 2009; Voermans et al., 2017; Kim et al., 2018), as well as with profiles of mass diffusivity measured in numerical experiments (Chandesris et al., 2013; Sherman et al., 2019). For this model, we assume that vertical mixing rates are highest at the SWI with $K_{z}=K_{e}$, followed by an exponential decay below the SWI to $K_{p}$ :

$$
K_{z}(z<0)=K_{p}+\left(K_{e}-K_{p}\right) e^{\alpha z} .
$$


We refer to this simulation case as "enhanced interfacial mixing." For this case, we allowed $K_{e}$ to vary during curve fitting, yielding three free parameters. To ensure this mixing profile was continuous across the SWI, we obtained $K_{z}$ for $z \in\left(0, z_{\max (K)}\right)$ by interpolating between the SWI and the elevation where eddy diffusivity was highest, $z_{\max (K)}$. Values of $z_{\max (K)}$ were 0.057, 0.071, $0.074 \mathrm{~m}$, for $\operatorname{Re} 11,000,21,000$, and 42,000 experiments, respectively. Interpolation was performed using Matlab's shape-preserving piecewise cubic interpolation ('pchip') scheme. Last, profiles were smoothed with a moving average filter (span $0.017 \mathrm{~m}$ ) to ensure they were differentiable at all elevations.

The particle tracking model was used to determine which hypothesized profile best described the vertical concentration distributions observed in continuous, steady state tracer injection experiments (Roche et al., 2018). Steady-state injections were simulated by introducing 200 virtual particles per time step, $\Delta t$. A value of $\Delta t=0.02 \mathrm{~s}$ was found to be sufficiently small for steady state concentration profiles to converge (i.e., profiles at $\Delta t=0.02 \mathrm{~s}$ differed by $<1.3 \%$ from profiles generated using simulations at $\Delta t=0.005 \mathrm{~s}$ ). Boundary conditions at $z=-d_{b}$ and $z=H$ were no flux. Two injection locations were simulated for each profile, matching conditions used in Roche et al. (2018): a "surface injection" at $(x, z)=(0,-0.006) \mathrm{m}$, and a "subsurface injection" at $(x, z)=(0,-0.082) \mathrm{m}$. Experimental and simulated concentrations were measured at a downstream location $x=0.476 \mathrm{~m}$ and at elevations of $z=-0.006,-0.044,-0.082$, $0.120,-0158$, and $-0.196 \mathrm{~m}$ within the bed. A sum of squared errors ( $S S E$ ) fitting function was used to account for subsurface concentrations and the overall fraction of mass retained in the bed:

$$
S S E=\sum_{i}\left(\sum_{z}\left(\frac{C_{E, i, z}-C_{M, i, z}}{\max \left(C_{E, i, z}\right)}\right)^{2}+2\left(f_{E, i}-f_{M, i}\right)^{2}\right) .
$$

Here, $C_{X, i, Z}$ are the experimental $(E)$ and modeled $(M)$ solute concentration measured at elevation $z$, respectively; and $f_{X, i}$ is the fraction of injected mass retained in the streambed. Fits were performed for each tracer injection elevation $(i=\operatorname{sur} f$, sub for surface and subsurface injections, respectively). Due to large concentration differences between surface and subsurface experiments, experimental concentrations were normalized by $\max \left(C_{E, i, z}\right)$ to weight each experiment approximately equally. Inclusion of $f_{X, i}$ in (6) ensured that model fits respected observed mass exchange with the water column; we used a weighting factor of 2 for this term so that the overall mass flux observed in each domain was given greater emphasis than any individual concentration measurement.

Model fits were used to calculate the depth of the enhanced mixing layer, $z_{\text {en }}$, defined as the location where the mixing rate was $1 \%$ greater than the underlying porewater dispersion $K_{p}$ :

$$
\frac{K_{z}\left(z_{e n}\right)-K_{p}}{K_{z}(0)-K_{p}}=0.01 \text {. }
$$

2.3 Reach scale simulations

Pulse injections of a conservative solute were simulated by particle tracking using different $u_{x}(\mathrm{z})$ profiles, $K_{z}(\mathrm{z})$ profiles, and streambed depths. These features were varied to 
assess each one's specific influence on breakthrough curves (BTCs) and hyporheic zone residence time distributions (RTDs). Simulation cases are listed in Table 2, resulting in a total of five cases. Note that the enhanced interfacial mixing profile was used in all reach-scale simulations with turbulent mixing in the streambed, since this profile captured experimental observations better than the monotonic mixing profile. For these cases, we used the parameter set $\left(K_{e}, \alpha, K_{p}\right)$ that provided the best fit to steady state experiments (See Section 2.2). To assess the influence of enhanced interfacial mixing on BTCs, the enhanced interfacial mixing profile was compared to a "uniform vertical mixing" profile $\left(K_{z}(\mathrm{z}<0)=K_{p}\right)$ in one simulation case (Table 2 , case $b$ ). This latter profile represents a conceptual endmember of both the enhanced interfacial mixing (i.e., $K_{e}=K_{p}$ ) and the monotonic decrease profiles (i.e., $\alpha \rightarrow \infty$ ).

A total of $N_{p}$ particles were released uniformly over the water column at $x=0$ and monitored for a minimum of 200,000 s. A value of $N_{p}=1.9 \times 10^{5}$ particles was used for RTD calculations (Table 2, Case a), and $N_{p}=10^{6}$ particles for all other cases. We determined the hyporheic zone RTD for each simulation by recording all events where a particle enters and then exits the region $z \in\left(-d_{b}, 0\right)$; we then calculated the distribution of elapsed times for each event. BTCs were determined as the first passage time distribution of particles in the water column:

$$
C(L, t)=N(L,(t, t+\Delta t)) \Delta t^{-1} N_{p}^{-1} .
$$

where $N$ represents the sum of first passage times from $(t, t+\Delta t)$ and $L$ is the length of the reach.

Simulation results were used to calculate several metrics associated with solute mixing and transport. The advective hyporheic timescale was defined as the time required to traverse the reach while traveling at the mean hyporheic zone velocity $\bar{U}_{H Z}$ :

$$
\tau_{a d v}=L / \bar{U}_{H Z} .
$$

The characteristic time of vertical mixing in the streambed, $\tau_{\text {bed }}$, was defined using the mean vertical mixing rate in the hyporheic zone, $\bar{K}_{H Z}$, as:

$$
\tau_{\text {bed }}=d_{b}^{2} / \bar{K}_{H Z} .
$$

\subsubsection{Comparison with stochastic modeling theory}

Random walk theory predicts that, if motions are governed by independent and identically distributed Gaussian displacements, a walker entering a semi-infinite streambed (i.e., $d_{b}=\infty$ ) will return to the SWI at time $t$ with probability $p(t) \sim t^{-1 / 2}$ (Feller, 1968; Bottacin-Busolin \& Marion, 2010; Aquino et al., 2015). This scaling holds when vertical mixing is uniform over all streambed depths. We therefore expected hyporheic zone RTDs from simulations to exhibit $p(t) \sim t^{-1 / 2}$ scaling, since vertical mixing was approximately uniform over the streambed (i.e., $\left.\left|d_{b}\right| \gg\left|z_{e n}\right|\right)$.

We compared reach-scale simulations with predictions from a mobile-immobile model based on continuous time random walk (CTRW) theory (Boano et al., 2007). In brief, this 1-D analytical model parses the stream into a mobile (water column) zone and an immobile (hyporheic) zone where solute is assumed to be motionless. Solute is conceptualized as an ensemble of infinitesimal particles, and each particle performs a 1-D random walk with identical 
and independently distributed jumps and waits. The distributions of jump lengths $\lambda(x)$ and wait times $\psi(t)$ are assumed to be independent in this formulation, which allows for a mathematically-tractable description of particle ensemble motion to be written as (Berkowitz et al., 2006):

$$
\frac{\partial C(x, t)}{\partial t}=\int_{0}^{t} M\left(t-t^{\prime}\right)\left[-U_{\Psi} \frac{\partial C\left(x, t^{\prime}\right)}{\partial x}+D_{\Psi} \frac{\partial^{2} C\left(x, t^{\prime}\right)}{\partial x^{2}}\right] d t^{\prime}
$$

Here, $U_{\Psi}=\bar{t}^{-1} \int x \lambda(x) \mathrm{d} x$ and $D_{\Psi}=\bar{t}^{-1} \int x^{2} \lambda(x) \mathrm{d} x$ are upscaled properties of the particle ensemble, representing in-stream velocity $U_{\Psi}$ and longitudinal dispersion $D_{\Psi}$, and $\bar{t}$ is a characteristic timescale. We assume $U_{\Psi}=\bar{U}_{S}$. We use a standard estimate for dispersion in open-channel flows (Fischer et al., 1979) to calculate $D_{\Psi}=5.93 \mathrm{Hu}$, where $u^{*}$ is the shear velocity. We assume $\bar{t}=L \bar{U}_{s}^{-1}$, equal to the mean transit time in the reach through the water column (Boano et al., 2007). $M(t)$ is a memory function that is controlled entirely by the rate of solute transfer from the water column to the hyporheic zone and the solute residence time distribution in the hyporheic zone, both described below. See Berkowitz et al. (2006) and Boano et al. (2007) for full details of the CTRW model derivation.

Mass transfer from the water column to the hyporheic zone is assumed to be a first-order removal rate $\Lambda\left(\mathrm{s}^{-1}\right)$. We estimated $\Lambda$ by observing the exponential decrease of (initially uniformly distributed) particles in the water column at early times. Solute entering the hyporheic zone at time 0 remains immobile until it returns to the stream at a time $t\left(\mathrm{~s}^{-1}\right)$ governed by the hyporheic residence time distribution, $\varphi(t)$. As a base case, we parameterize $\varphi(t)$ as an asymptotic power-law distribution, $\varphi(t) \sim t^{-\beta}$. An asymptotic expression for $\varphi(t)$ exists in Laplace space $\left(\tilde{f}(u)=\int_{0}^{\infty} e^{-u t} f(t) d t\right)$ :

$$
\tilde{\varphi}(u)=\frac{1}{1+c_{\beta} u^{\beta}}
$$

where $\beta=1 / 2$ expected from predictions, and $c_{\beta}$ determines the onset of power-law tailing in $\tilde{\varphi}(u)$ (Berkowitz et al., 2006 ). We could find no physical basis for calculating $c_{\beta}$ from simulation results and therefore set it to $c_{\beta}=1$ for consistency with past convention (Cortis \& Berkowitz, 2005), leaving zero free parameters. Asymptotic solutions for the CTRW model predict that late-time concentrations in the water column will follow $C(t) \propto t^{-(1+\beta)}$, which indicates that late time concentrations will approach $C(t) \propto t^{-3 / 2}$ in our simulations (Aquino et al., 2015; Bottacin-Busolin, 2017). Note that, with this parameterization, the CTRW model is equivalent to the fractional-order mobile-immobile model, which implicitly assumes a heavytailed power-law wait time distribution (Schumer et al., 2003; Chakraborty et al., 2009; Kelly et al., 2017).

The distribution $\varphi(t)$ will not follow the expected $\sim t^{-1 / 2}$ scaling at early times when turbulence enhances hyporheic mixing, since the mixing rate is non-uniform in a transition layer below the SWI. We tested a modified $\tilde{\varphi}(u)$ to evaluate if measurable features of enhanced interfacial mixing can be incorporated into the CTRW model. Here, the hyporheic zone is conceptualized as two retention zones in series. The upper retention zone is assumed to be perfectly mixed. Transfer from the perfectly mixed layer to the deeper layer occurs at rate $\Lambda_{e n}$. 
The rapidly decaying (i.e., non-uniform) vertical mixing profile implies that the enhanced mixing layer is smaller in simulations than what was observed in experiments, i.e., $\alpha^{-1}<0.076 \mathrm{~m}$ (Roche et al., 2018). Rapid particle crossings of the SWI in the interval $z \in\left(-\alpha^{-1}, 0\right)$ are an inherent outcome of the random walk algorithm, which prevented us from calculating $\Lambda_{e n}$ using the same method as for estimating $\Lambda$ (see above). We therefore modeled $\Lambda_{\mathrm{en}}$ as a free parameter, and set the extent of the upper retention zone to $-0.076 \mathrm{~m}$ for all flowrates. Again, this region is assumed to be perfectly mixed, following an exponential distribution with mean residence time $\mu_{e n}$, taken directly from simulations (Figure 3). The RTD of the deeper hyporheic layer is parameterized using Equation (12). The model thus contains one free parameter, $\Lambda_{\mathrm{en}}$. Equations were solved numerically using a modified version of the CTRW Toolbox (Cortis \& Berkowitz, 2005). All simulations were performed in Matlab version r2017b (Mathworks, Cambridge, MA, USA).

The timescales associated with the finite bed depth impose constraints that modify the streambed RTD. We define $\tau_{b e d}$ as the timescale for vertical mixing throughout the bed. By this definition, $\tau_{b e d}$ is a predictor of the Gaussian setting timescale, or the time after which a longitudinally spreading tracer will evolve according to Fickian theory (Taylor, 1954; Fischer et al., 1979; Zhang \& Meerschaert, 2011). This constraint implies that solute RTDs will approach $p(t) \sim t^{-1 / 2}$, followed by a transition to exponential decay (tempering) at approximately $\tau_{b e d}$. Consequently, BTCs will also show tempering behavior after this timescale.

\section{Results}

\subsection{Hyporheic mixing profiles}

Measured and modeled concentration profiles are shown for each flowrate in Figure 2. The monotonic profile could not capture the enhanced interfacial mass exchange, resulting in model concentrations that exceeded experimental concentrations near the SWI. The fitting algorithm increased porewater dispersion, $K_{p}$, in order to increase fluxes of the injeted solute from the bed. As a consequence, the simulated concentrations were greater than experimental concentrations at nearly all locations in the streambed.

Results improved substantially for simulations parameterized with the enhanced interfacial mixing profile. Model simulations better matched the observed concentration profiles, particularly near the SWI (Figure 2). The decay rate of mixing in the bed, $\alpha$, was similar for $R e$ 21,000 and 42,000, and the region of enhanced mixing reached $\left|z_{e n}\right|=0.073 \mathrm{~m}$ and $\left|z_{\text {en }}\right|=$ $0.063 \mathrm{~m}$, respectively. Results from $\operatorname{Re} 11,000$ simulations were far less sensitive to $\alpha$, due to the relatively small mixing rate at the SWI, $K_{e}$ (Table 3 and supporting information). The average mixing rate in the enhanced mixing region was just $24 \%$ of the mean water column mixing rate at $\operatorname{Re} 11,000$, compared with $46 \%$ and $40 \%$ at $\operatorname{Re} 21,000$ and 42,000, respectively (Table 3). These results indicate that turbulence did not substantially impact subsurface mixing in $R e$ 11,000 simulations.

\subsection{Reach-scale simulations}

\subsubsection{Influence of flowrate on streambed residence time distributions}

Streambed RTDs match the predicted $\sim t^{-1 / 2}$ scaling over a broad range of times (Figure 3 , black dots). Deviations from this scaling are controlled at early times by enhanced mixing 
below the SWI, and at late times by the impermeable boundary at $-d_{b}$. In the zone just below the SWI, $z \in(-0.08 \mathrm{~m}, 0 \mathrm{~m})$, RTDs closely matched an exponential distribution (Figure 3, light dots; see supporting information). The exponential shape of RTDs in this zone indicates that solute is well mixed, justifying the use of a well-mixed interfacial layer in the modified mobile-immobile CTRW model (see Section 3.2.2). Mixing intensity decreases in $z \in(-0.08 \mathrm{~m}, 0 \mathrm{~m})$ as $R e$ decreases, resulting in larger residence times.

All full-streambed RTDs are exponentially tempered at late times. The transition from $t^{-1 / 2}$ scaling to exponential tempering occurs at approximately the characteristic timescale $\tau_{b e d}$ associated with complete vertical mixing in the streambed. The value of $R e$ directly controls $\tau_{\text {bed }}$ by increasing vertical mixing rates through the hyporheic zone. As a result, $\tau_{\text {bed }}$ increases from $2.6 \times 10^{4} \mathrm{~s}$ at $\operatorname{Re} 42,000 \mathrm{~s}$ to $14.9 \times 10^{4} \mathrm{~s}$ at $\operatorname{Re} 11,000$ (Figure 3 ).

3.2.2 Comparison of simulation with uniform vertical mixing and simulation with enhanced vertical mixing in the streambed

All BTCs follow the predicted $t^{-3 / 2}$ scaling over a wide range of times in simulations with enhanced vertical mixing and simulations with uniform vertical mixing $\left(K_{z}(\mathrm{z}<0)=K_{p}\right)$. The simulation with uniform mixing $\left(K_{z}(\mathrm{z}<0)=K_{p}\right.$; Figure 4 black dots $)$ is well described by the CTRW model with parameter values based on simulation results $\left(\bar{U}_{s}, D, \Lambda\right.$, and $\left.\beta\right)$, and zero degrees of freedom (Figure 4 black line, Table 4).

The peak of the solute plume clearly arrives later in the enhanced mixing case (Figure 4, light blue dots) compared with the uniform mixing case. The immobilization rate, $\Lambda$, is $\sim 3 \times$ higher in the enhanced mixing case than in the uniform mixing case, indicating faster mass transfer from the water column to the hyporheic zone. Streamwise hyporheic velocities are zero in both simulations, meaning that the delayed arrival of the tracer peak is caused by enhanced mass delivery and retention within the hyporheic zone. Additionally, the BTC for the enhanced mixing case decreases exponentially over an extended interval of times, since rapid mixing below the SWI creates a region where residence times are approximately exponentially distributed (Figure 3a). As a result, the onset of $\sim t^{-3 / 2}$ power-law tailing is delayed until a time when mass has sufficiently sampled the region of uniform mixing deeper in the hyporheic zone.

The modified CTRW model conceptualizes the hyporheic zone as an instantaneously mixed zone (i.e., with exponential RTD) for $z=(-0.08 \mathrm{~m}, 0 \mathrm{~m})$, which exchanges mass with a zone of uniform vertical mixing for $z<-0.08 \mathrm{~m}$. Mass transfer from the rapidly mixed zone to the deeper zone occurs at rate $\Lambda_{e n}=0.02 \mathrm{~s}^{-1}$, based on fits to modeled BTCs. The deeper hyporheic subdomain is identical to the hyporheic RTD for the uniform mixing case, parameterized as an asymptotic power law with $p(t) \sim t^{-1 / 2}$. The model provides a good fit to concentrations for nearly all times after peak arrival (Figure 4), which demonstrates the strength of the CTRW modeling framework when model parameters are based on physically-based measures. Differences at early times between simulation results and the CTRW model fit are likely due to the asymmetry of $K_{z}$ below the SWI. High $K_{z}$ at the SWI signifies a high likelihood of particles exchanging between the water column and the hyporheic zone after very short times. These rapid exchanges increase longitudinal spreading of mass in the domain, but the effect is not captured in the CTRW model since the longitudinal dispersion estimate $D_{\Psi}=5.93 \mathrm{Hu}$ is based on mixing theory for open channel flows with impermeable beds (Fischer et al., 1979). 
3.2.3 Comparison of simulations with zero streamwise hyporheic velocity and measured streamwise hyporheic velocity

Simulations using experimentally-measured hyporheic velocities differ substantially from simulations with zero streamwise velocity in the hyporheic zone (Figure 5). Concentrations in both simulations are similar at, and shortly after, the passing of the plume peak. However, concentrations for the case using measured streamwise hyporheic velocities exhibit a steeper power-law slope than the predicted $\sim t^{-3 / 2}$ scaling (Figure 5 colored dots). They also show rapid tempering at approximately $\tau_{a d v}$, which is the maximum residence time for the reach, set by advective longitudinal washout of tracer mass from the hyporheic zone (Equation 9). Differences between these two simulations cannot be captured by making additional physically-based modifications to the CTRW model used here; nonzero streamwise velocities in the hyporheic zone violate the model assumption that these velocities are negligible compared to streamwise velocities in the water column.

3.2.4 Comparison of BTCs for simulations with the measured streamwise hyporheic velocity profile and different streambed depths

Exponential tempering of BTCs is also controlled by the characteristic timescale for mixing over the full depth of the streambed, $\tau_{\text {bed }}$. This time scale is the Gaussian setting time, after which the plume reverts to a Gaussian shape and features of the BTC associated with the hyporheic zone RTD are no longer visible. In our simulations, tempering of BTCs after $\tau_{\text {bed }}$ is more gradual than tempering of BTCs following $\tau_{a d v}$ (Figure $6 \mathrm{~b}$, green dots). The dominant process controlling tempering of the power-law BTC tail can be determined from the relative magnitude of the advective washout and Gaussian setting timescales. Cases with $\tau_{\text {adv }} / \tau_{\text {bed }}<\sim 2$ show much steeper exponential BTC tempering consistent with a tempering time set by the advective washout timescale. Conversely, cases with $\tau_{\text {adv }} / \tau_{\text {bed }}>\sim 2$ show broad exponential tempering associated with Gaussian setting. This condition is only met in Figure $6 \mathrm{~b}$ for the BTC at $L=250 \mathrm{~m}$ and a $0.5 \mathrm{~m}$ streambed $\left(\tau_{a d v} / \tau_{\text {bed }} \approx 3\right)$. For a fixed stream geometry, simulated pulse injections can only control the ratio $\tau_{a d v} / \tau_{\text {bed }}$ through modification of reach length ( $\tau_{a d v}=L \bar{U}_{H Z}$ ), since $\tau_{b e d}$ is determined entirely from properties of the streambed. Reach length therefore controls if $\tau_{\text {bed }}$ is observable in BTCs, as illustrated by the differences between $50 \mathrm{~m}$ and $250 \mathrm{~m} \mathrm{BTCs}$ for the reach with a $0.5-\mathrm{m}$ bed (Figure 6, green curves).

3.2.5 Influence of streambed depth on streambed residence time distribution and overall mass recovery

The tempering timescale $\tau_{\text {bed }}$ decreases with decreasing streambed depth, thereby reducing the interval of times over which $p(t) \sim t^{-1 / 2}$ scaling is observed in streambed RTDs (Figure 7a). The power-law scaling regime disappears for sufficiently small streambed depths. In these cases, hyporheic mixing is dominated by turbulence at nearly all depths, and RTDs are approximately exponential due to near perfect mixing below the SWI. The shape of BTC tails is approximately exponential in these cases, with no power-law scaling regime (results not shown).

Streambed depth also determines the overall mass recovery, defined as the fraction of total tracer particles exiting the reach through the water column. For a pulse injection in the water column, mobile zone mass recovery decreases asymptotically to the fraction of total discharge in the water column, $\bar{U}_{S} H /\left(\bar{U}_{S} H+\bar{U}_{H Z} d_{b}\right)$ (Figure $7 \mathrm{~b}$, dotted lines). This value is 
reached within relatively short reach lengths for simulations with very shallow streambeds, due to fast mixing in the region of enhanced turbulence below the SWI. However, very large $\left(\geq 10^{3}\right.$ $\mathrm{m})$ reach lengths are required for this asymptotic limit to be observable in simulations with streambeds greater than $\sim 0.5 \mathrm{~m}$, due to much slower vertical mixing deeper in the bed.

\section{Discussion}

Turbulent coherent structures episodically propagate across the SWI in coarse-sediment streams, creating an interfacial zone where turbulent stresses and mixing rates are elevated (Blois et al., 2012; Roche et al., 2018). As a result, profiles of turbulent momentum and mass diffusivity can reach their maximum near the SWI. This profile shape differs from the prevailing assumption that vertical mixing rates are highest in the water column and decay monotonically across the SWI (Zhou \& Mendoza, 1993; Chandler et al., 2016; Li et al., 2017). The depth of the enhanced mixing layer decreases with decreasing stream $R e$, and disappears as in-stream turbulence becomes too weak to penetrate the SWI (Figures 2,3). This result supports previouslyreported findings that the depth of turbulence penetration in the streambed varies dynamically with streamflow (Manes et al., 2012; Voermans et al., 2017).

Spatial variability of mixing in the hyporheic zone ultimately impacts solute retention at the reach scale $(>50 \mathrm{~m})$. Solute entering the enhanced mixing layer is either rapidly flushed to the water column or delivered to deeper, slower moving porewaters. This causes hyporheic zone RTDs to deviate at short times from the theoretical $p(t) \sim t^{-1 / 2}$ scaling expected for a streambed with uniform mixing at all depths (Figure 3). Consequently, BTCs do not match CTRW model predictions based on the theoretical RTD (Figure 4). Predictions improve when the CTRW model is modified to represent the enhanced mixing layer as a well mixed zone, coupled to a zone of uniform mixing. For simulations with zero streamwise velocities in the hyporheic zone, the modified model fully describes the observed transition from exponential BTC tailing at intermediate times to the expected $\sim t^{-3 / 2}$ tailing at late times. The power-law tailing interval transitions to an exponential tempering interval at approximately $\tau_{\text {bed }}$ (Figure 6b). This timescale represents a physically-based constraint on the maximum hyporheic residence time. Alternative formulations of the mobile-immobile CTRW model could potentially account for BTC tempering at this physically-limiting timescale, for example, a model parameterized with a truncated power-law RTD (Dentz et al., 2004) that also tempers at $\tau_{\text {bed }}$.

In field studies, observation of all key BTC features (i.e., peak arrival, intermediate exponential decay, power-law decay, and late-time tempering) is desirable because it indicates the physical controls of hyporheic mixing and residence times, which otherwise would require direct subsurface measurements to estimate (Ward et al., 2010; Briggs et al., 2012; Singha et al., 2015). Several factors control whether all BTC features are observable. The minimum condition for interpretation of 1-D longitudinal transport is that reach length must be sufficiently long for injected solute to be fully mixed in the water column (Fischer et al., 1979). Exponential BTC tailing is expected to be observed in BTCs at this length scale, since turbulent eddies rapidly deliver mass to the enhanced interfacial mixing layer (Roche et al., 2018). Power-law tailing in BTCs is expected when additional retention mechanisms in the stream, such as slower and longer-distance hyporheic transport, result in power-law distributed residence times. In our simulations, uniform vertical mixing below the enhanced mixing layer causes power-law scaling of the streambed RTD (Figures 1,4). The timescale of power-law tailing in RTDs decreases with 
decreasing streambed depth, and the hyporheic RTD approaches an exponential distribution when the enhanced interfacial mixing layer extends over the full depth of the streambed (Figure 7a).

Late-time tempering associated with a physically-limiting timescale, such as $\tau_{b e d}$, is often not observed in field studies due to limited experimental observation times and/or tracer concentrations falling below detection limits (Drummond et al., 2012). Reach length determines the relative balance of $\tau_{b e d}$ to the characteristic travel time in the reach, $\tau_{R}=L / \bar{U}_{S}$ (Harvey \& Wagner, 2000). The signature of hyporheic retention can only be observed in BTCs when $\tau_{R} \leq$ $\tau_{\text {bed }}$, since the tracer plume transitions to a regular Fickian transport regime - integrated over both the water column and streambed - at approximately $\tau_{\text {bed }}$ (Zhang \& Meerschaert, 2011). Prior studies have shown that the balance of streamwise advection and hyporheic exchange timescales can be used to determine a reach length that ensures all features of hyporheic retention are observable in BTCs (e.g., (Harvey \& Wagner, 2000)@ @author-year). Our simulations using experimentally-measured hyporheic velocities indicate that the range of observable BTC features is additionally constrained by the timescale of longitudinal tracer washout from the hyporheic zone, $\tau_{a d v}$ (Figure 6). Since $\tau_{a d v}$ is directly proportional to reach length (i.e., $\tau_{a d v}=L / \bar{U}_{H Z}$ ), reach length influences the balance of $\tau_{a d v}$ and $\tau_{b e d}$. In our simulations, $\tau_{a d v} / \tau_{b e d}>\sim 2$ is a necessary condition for tempering associated with the longest retention timescale $\tau_{\text {bed }}$ to be observable.

The predicted $\sim t^{-3 / 2}$ tailing is only observed in BTCs for simulations with streamwise hyporheic velocities set to zero (Figure 5). The CTRW model used here captures the $\sim t^{-3 / 2}$ power-law slope because the model implicitly assumes that streamwise velocities in the hyporheic zone are negligible compared to water column velocities (Boano et al., 2007). This assumption implies that the distribution of long transit times through the reach is approximately equal to the distribution of residence times in transient storage zones, which is commonly assumed in 1-D transport models (Bencala \& Walters, 1983; Haggerty et al., 2002; Schumer et al., 2003; Marion, Zaramella, et al., 2008). While our results indicate that streamwise hyporheic velocities can only be considered negligible when $\bar{U}_{S} / \bar{U}_{H Z}>\sim 30$, simulations by Sherman et al. (2019) show that this assumption can only be made for $\bar{U}_{S} / \bar{U}_{H Z}>\sim 100$. At lower ratios, the timescale of longitudinal hyporheic advection represents an additional control on reach-scale transit times, as tracer propagates out of the reach longitudinally in the streambed. In these cases, BTC tailing is steeper than the $\sim t^{-3 / 2}$ prediction (Figure 5), BTCs temper rapidly at $\tau_{a d v}$ (Figures 5,6), and mass recovery is incomplete when based on concentration observations in the water column (Figure 7b). We expect similar deviations from asymptotic predictions for higherorder temporal BTC moments, plume peak location, and plume peak concentration when predictions are based on the assumption that streamwise velocities are negligible in the immobile zone (Aquino et al., 2015; Bottacin-Busolin, 2017). No mobile-immobile model will capture these changes while simultaneously respecting the physics of hyporheic transport, since no immobile zone exists for these cases.

Our results suggest that new theory is needed to capture the space-time coupling associated with streamwise hyporheic advection through high permeability streams. Within the CTRW framework, new advancements may be achieved by returning to the Generalized Master Equations and reconsidering the separation of velocity timescales between the stream and streambed. Rather than representing transport as a random walk between mobile and immobile 
domains (à la Schumer et al., 2003), the model can be reformulated to consider the solute velocity in each domain (Klafter et al., 1987; Zumofen \& Klafter, 1993; Dentz et al., 2008).

\section{Conclusions}

This study adds to a growing literature that confirms turbulence directly controls mixing in highly-permeable porous media (Ghisalberti, 2009; Katul et al., 2013; Voermans et al., 2018). Comparison of simulated and observed tracer injections in a coarse-grained streambed shows that vertical mixing is highest at the SWI and decays exponentially with depth. Further, both enhanced interfacial mixing and streamwise hyporheic velocities directly control reach-scale solute retention in coarse-grained streambeds. For pulse injections, rapid mixing at the SWI creates an interval of exponential tailing in BTCs at intermediate times, prior to the onset of power-law tailing. High streamwise velocities in the hyporheic zone cause tracer to exit the stream reach through the hyporheic zone, which results in incomplete mass recovery in the water column and steeper BTC slopes than predictions from a mobile-immobile CTRW model.

Our findings have direct implications for the transformation of reactive solutes in streams. Reach-scale transformation depends strongly on the covariation of reactivity and mixing across the SWI (Li et al., 2017). For example, nutrient uptake associated with microbial metabolism varies strongly with streambed depth, with rates often decreasing monotonically into the bed (Inwood et al., 2007; Harvey et al., 2013; Knapp et al., 2017; Li et al., 2017). The enhanced interfacial mixing rates observed here imply that nutrients consumed in the most metabolically active region of the streambed are rapidly replenished, which causes this region to contribute disproportionately to overall uptake. A mechanistic description of turbulent interfacial mixing is therefore essential for estimating nutrient transformation at the reach scale. Recently, Grant, Azizian, et al. (2018) developed a new scaling model to show that in-stream turbulence sets a physical limit on reach-scale nutrient uptake, which demonstrates how measurable features of the flow field can be used directly to estimate stream metabolism. Improved estimates of metabolism in high-permeability streambeds will require models that quantify the variability of vertical mixing, downstream advection, and nutrient uptake rates in the hyporheic zone.

Development of depth-dependent mixing models generally requires high-frequency measurements of both velocity and concentration (Chandler et al., 2016). Due to the challenge of making these measurements in natural streams, models applied to date have been based on a limited range of observed conditions. Experiments over a greater range of stream flows, channel geometries, and streambed sediment types are needed to generalize current model formulations and verify their applicability in natural streams. These efforts will help clarify the importance of turbulent interfacial mixing compared to other known transport mechanisms, such as advective pumping through bedforms (Packman et al., 2004; Blois et al., 2014; Sinha et al., 2017). Further, tracer injections combined with detailed stream and hyporheic measurements will enable identification of the lower limit of $\bar{U}_{S} / \bar{U}_{H Z}$, which corresponds to the conditions at which streamwise hyporheic velocities can be considered negligible and classical mobile-immobile transport models can be used (Haggerty et al., 2002; Schumer et al., 2003; Boano et al., 2007).

\section{Acknowledgments, Samples, and Data}

We gratefully acknowledge funding from National Science Foundation grants EAR1215898, EAR-1344280, EAR-1351625, and the Department of the Army, U.S. Army Research Office grant W911NF-15-1-0569, and a Northwestern Terminal Year Fellowship to KRR. 
Supporting data are available at DOI: 10.6084/m9.figshare.4244405. We thank Associate Editor Daniel Fernàndez-Garcia and two anonymous referees for comments that helped us substantially improve the quality of this manuscript.

\section{References}

Allen, M., \& Tildesley, D. (1987). Molecular Simulation of Liquids. Clarendon, Oxford.

Aquino, T., Aubeneau, A., \& Bolster, D. (2015). Peak and tail scaling of breakthrough curves in hydrologic tracer tests. Advances in Water Resources, 78, 1-8. http://www.sciencedirect.com/science/article/pii/S0309170815000184

Aubeneau, A. F., Hanrahan, B., Bolster, D., \& Tank, J. (2016). Biofilm growth in gravel bed streams controls solute residence time distributions. Journal of Geophysical Research: Biogeosciences, 121(7), 1840-1850. http://dx.doi.org/10.1002/2016JG003333

Battin, T. J., Besemer, K., Bengtsson, M. M., Romani, A. M., \& Packmann, A. I. (2016). The ecology and biogeochemistry of stream biofilms. Nat Rev Micro, 14(4), 251-263. Review. http://dx.doi.org/10.1038/nrmicro.2016.15

Battin, T. J., Sloan, W. T., Kjelleberg, S., Daims, H., Head, I. M., Curtis, T. P., \& Eberl, L. (2007). Microbial landscapes: new paths to biofilm research. Nature Reviews Microbiology, 5(1), 76-81. $\mathrm{http} / / / \mathrm{www}$.nature.com/nrmicro/journal/v5/n1/abs/nrmicro1556.html

Bear, J. (1979). Hydraulics of groundwater: Courier Corporation.

Bencala, K. E., \& Walters, R. A. (1983). Simulation of Solute Transport in a Mountain Pool-and-Riffle Stream - a Transient Storage Model. Water Resources Research, 19(3), 718-724.

Berkowitz, B., Cortis, A., Dentz, M., \& Scher, H. (2006). Modeling non-Fickian transport in geological formations as a continuous time random walk. Reviews of Geophysics, 44(2).

Blois, G. L., Best, J. L., Christensen, K. T., Hardy, R. J., \& Smith, G. H. S. (2013). Coherent Flow Structures in the Pore Spaces of Permeable Beds Underlying a Unidirectional Turbulent Boundary Layer: A Review and Some New Experimental Results. In Coherent Flow Structures at Earth's Surface (pp. 43-62): John Wiley $\&$ Sons, Ltd.

Blois, G. L., Best, J. L., Sambrook Smith, G. H., \& Hardy, R. J. (2014). Effect of bed permeability and hyporheic flow on turbulent flow over bed forms. GEOPHYSICAL RESEARCH LETTERS, 41(18), 6435-6442. http://dx.doi.org/10.1002/2014GL060906

Blois, G. L., Sambrook Smith, G. H., Best, J. L., Hardy, R. J., \& Lead, J. R. (2012). Quantifying the dynamics of flow within a permeable bed using time-resolved endoscopic particle imaging velocimetry (EPIV). Experiments in Fluids, 53(1), 51-76.

Boano, F., Harvey, J. W., Marion, A., Packman, A. I., Revelli, R., Ridolfi, L., \& Wörman, A. (2014). Hyporheic flow and transport processes: Mechanisms, models, and biogeochemical implications. Reviews of Geophysics, 52(4), 603-679. http://dx.doi.org/10.1002/2012RG000417

Boano, F., Packman, A., Cortis, A., Revelli, R., \& Ridolfi, L. (2007). A continuous time random walk approach to the stream transport of solutes. Water Resources Research, 43(10), W10425. http://www.agu.org/pubs/crossref/2007/2007WR006062.shtml

Boano, F., Revelli, R., \& Ridolfi, L. (2011). Water and solute exchange through flat streambeds induced by large turbulent eddies. Journal of Hydrology, 402(3-4), 290-296. http://www.sciencedirect.com/science/article/pii/S0022169411002034

Bottacin-Busolin, A., \& Marion, A. (2010). Combined role of advective pumping and mechanical dispersion on time scales of bed form-induced hyporheic exchange. Water Resources Research, 46(8). http://dx.doi.org/10.1029/2009WR008892

Bottacin-Busolin, A., Singer, G., Zaramella, M., Battin, T. J., \& Marion, A. (2009). Effects of Streambed Morphology and Biofilm Growth on the Transient Storage of Solutes. Environmental Science \& Technology, 43(19), 7337-7342. http://dx.doi.org/10.1021/es900852w

Bottacin-Busolin, A. (2017). Non-Fickian dispersion in open-channel flow over a porous bed. Water Resources Research, 53(8), 7426-7456. https://agupubs.onlinelibrary.wiley.com/doi/abs/10.1002/2016WR020348

Boulton, A. J., Findlay, S., Marmonier, P., Stanley, E. H., \& Valett, H. M. (1998). The functional significance of the hyporheic zone in streams and rivers. Annual Review of Ecology and Systematics, 29(1), 59-81. http://annualreviews.org/doi/abs/10.1146/annurev.ecolsys.29.1.59 
Breugem, W. P., Boersma, B. J., \& Uittenbogaard, R. E. (2006). The influence of wall permeability on turbulent channel flow. Journal of Fluid Mechanics, 562, 35-72. http://journals.cambridge.org/article_S0022112006000887

Briggs, M. A., Gooseff, M. N., Arp, C. D., \& Baker, M. A. (2009). A method for estimating surface transient storage parameters for streams with concurrent hyporheic storage. Water Resources Research, 45(4). https://agupubs.onlinelibrary.wiley.com/doi/abs/10.1029/2008WR006959

Briggs, M. A., Lautz, L. K., McKenzie, J. M., Gordon, R. P., \& Hare, D. K. (2012). Using high-resolution distributed temperature sensing to quantify spatial and temporal variability in vertical hyporheic flux. Water Resources Research, 48(2). https://agupubs.onlinelibrary.wiley.com/doi/abs/10.1029/2011WR011227

Cardenas, M. B., \& Wilson, J. L. (2007). Dunes, turbulent eddies, and interfacial exchange with permeable sediments. Water Resources Research, 43(8).

Chakraborty, P., Meerschaert, M. M., \& Lim, C. Y. (2009). Parameter estimation for fractional transport: A particletracking approach. Water Resources Research, 45(10). https://agupubs.onlinelibrary.wiley.com/doi/abs/10.1029/2008WR007577

Chandesris, M., D'Hueppe, A., Mathieu, B., Jamet, D., \& Goyeau, B. (2013). Direct numerical simulation of turbulent heat transfer in a fluid-porous domain. Physics of Fluids (1994-present), 25(12), 125110.

Chandler, I. D., Guymer, I., Pearson, J. M., \& van Egmond, R. (2016). Vertical variation of mixing within porous sediment beds below turbulent flows. Water Resources Research, 52(5), 3493-3509. http://dx.doi.org/10.1002/2015WR018274

Cortis, A., \& Berkowitz, B. (2005). Computing "anomalous" contaminant transport in porous media: The CTRW MATLAB toolbox. Groundwater, 43(6), 947-950.

Delay, F., Ackerer, P., \& Danquigny, C. (2005). Simulating solute transport in porous or fractured formations using random walk particle tracking. Vadose Zone Journal, 4(2), 360-379.

Dentz, M., Cortis, A., Scher, H., \& Berkowitz, B. (2004). Time behavior of solute transport in heterogeneous media: transition from anomalous to normal transport. Advances in Water Resources, 27(2), 155 - 173. http://www.sciencedirect.com/science/article/pii/S0309170803001726

Dentz, M., Scher, H., Holder, D., \& Berkowitz, B. (2008). Transport behavior of coupled continuous-time random walks. Physical Review E, 78(4), 041110.

Drummond, J., Covino, T., Aubeneau, A., Leong, D., Patil, S., Schumer, R., \& Packman, A. (2012). Effects of solute breakthrough curve tail truncation on residence time estimates: A synthesis of solute tracer injection studies. Journal of Geophysical Research: Biogeosciences (2005--2012), 117(G3).

Ensign, S. H., \& Doyle, M. W. (2005). In-channel transient storage and associated nutrient retention: Evidence from experimental manipulations. Limnology and Oceanography, 50(6), 1740-1751. http://dx.doi.org/10.4319/lo.2005.50.6.1740

Feller, W. (1968). An introduction to probability theory and its applications (Vol. 2): John Wiley \& Sons.

Fischer, H. B., List, J. E., Koh, C. R., Imberger, J., \& Brooks, N. H. (1979). Mixing in inland and coastal waters.

Ghisalberti, M. (2009). Obstructed shear flows: similarities across systems and scales. Journal of Fluid Mechanics, 641, 51-61.

Gooseff, M. N., LaNier, J., Haggerty, R., \& Kokkeler, K. (2005). Determining in-channel (dead zone) transient storage by comparing solute transport in a bedrock channel--alluvial channel sequence, Oregon. Water Resources Research, 41(6).

Grant, S. B., Azizian, M., Cook, P., Boano, F., \& Rippy, M. A. (2018). Factoring stream turbulence into global assessments of nitrogen pollution. Science, 359(6381), 1266. 10.1126/science.aap8074. http://science.sciencemag.org/content/359/6381/1266.abstract

Grant, S. B., Gomez-Velez, J. D., \& Ghisalberti, M. (2018). Modeling the Effects of Turbulence on Hyporheic Exchange and Local-to-Global Nutrient Processing in Streams. Water Resources Research, $0(0)$. https://agupubs.onlinelibrary.wiley.com/doi/abs/10.1029/2018WR023078

Haggerty, R., Wondzell, S. M., \& Johnson, M. A. (2002). Power-law residence time distribution in the hyporheic zone of a 2nd-order mountain stream. GEOPHYSICAL RESEARCH LETTERS, 29(13), 18-11.

Harvey, J. W., Böhlke, J. K., Voytek, M. A., Scott, D., \& Tobias, C. R. (2013). Hyporheic zone denitrification: Controls on effective reaction depth and contribution to whole-stream mass balance. Water Resources Research, 49(10), 6298-6316. http://dx.doi.org/10.1002/wrcr.20492

Harvey, J. W., \& Wagner, B. J. (2000). Quantifying hydrologic interactions between streams and their subsurface hyporheic zones. 
Higashino, M., Clark, J. J., \& Stefan, H. G. (2009). Pore water flow due to near-bed turbulence and associated solute transfer in a stream or lake sediment bed. Water Resources Research, 45(12), n/a-n/a. http://dx.doi.org/10.1029/2008WR007374

Inwood, S. E., Tank, J. L., \& Bernot, M. J. (2007). Factors Controlling Sediment Denitrification in Midwestern Streams of Varying Land Use. Microbial Ecology, 53(2), 247-258. journal article. http://dx.doi.org/10.1007/s00248-006-9104-2

Jackson, T. R., Haggerty, R., \& Apte, S. V. (2013). A fluid-mechanics based classification scheme for surface transient storage in riverine environments: quantitatively separating surface from hyporheic transient storage.

Karwan, D. L., \& Saiers, J. E. (2012). Hyporheic exchange and streambed filtration of suspended particles. Water Resources Research, 48(1), n/a-n/a. http://dx.doi.org/10.1029/2011WR011173

Katul, G. G., Cava, D., Siqueira, M., \& Poggi, D. (2013). Scalar turbulence within the canopy sublayer. Coherent flow structures at Earth's Surface, 73-95.

Kelly, J. F., Bolster, D., Meerschaert, M. M., Drummond, J. D., \& Packman, A. I. (2017). FracFit: A robust parameter estimation tool for fractional calculus models. Water Resources Research, 53(3), 2559-2567.

Kim, T., Blois, G., Best, J. L., \& Christensen, K. T. (2018). Experimental study of turbulent flow over and within cubically packed walls of spheres: Effects of topography, permeability and wall thickness. International Journal of Heat and Fluid Flow, 73, 16-29. http://www.sciencedirect.com/science/article/pii/S0142727X17311670

Klafter, J., Blumen, A., \& Shlesinger, M. F. (1987). Stochastic pathway to anomalous diffusion. Physical Review A, 35(7), 3081.

Knapp, J. L. A., González-Pinzón, R., Drummond, J. D., Larsen, L. G., Cirpka, O. A., \& Harvey, J. W. (2017). Tracer-based characterization of hyporheic exchange and benthic biolayers in streams. Water Resources Research, 53(2), 1575-1594. http://dx.doi.org/10.1002/2016WR019393

Li, A., Aubeneau, A. F., Bolster, D., Tank, J. L., \& Packman, A. I. (2017). Covariation in patterns of turbulencedriven hyporheic flow and denitrification enhances reach-scale nitrogen removal. Water Resources Research. http://dx.doi.org/10.1002/2016WR019949

Manes, C., Pokrajac, D., McEwan, I., \& Nikora, V. (2009). Turbulence structure of open channel flows over permeable and impermeable beds: A comparative study. Physics of Fluids (1994-present), 21(12), 125109. http://scitation.aip.org/content/aip/journal/pof2/21/12/10.1063/1.3276292

Manes, C., Pokrajac, D., Nikora, V., Ridolfi, L., \& Poggi, D. (2011). Turbulent friction in flows over permeable walls. GEOPHYSICAL RESEARCH LETTERS, 38(3).

Manes, C., Ridolfi, L., \& Katul, G. (2012). A phenomenological model to describe turbulent friction in permeablewall flows. GEOPHYSICAL RESEARCH LETTERS, 39(14), n/a-n/a. http://dx.doi.org/10.1029/2012GL052369

Marion, A., Packman, A. I., Zaramella, M., \& Bottacin-Busolin, A. (2008). Hyporheic flows in stratified beds. Water Resources Research, 44(9), n/a-n/a. http://dx.doi.org/10.1029/2007WR006079

Marion, A., Zaramella, M., \& Bottacin-Busolin, A. (2008). Solute transport in rivers with multiple storage zones: The STIR model. Water Resources Research, 44(10). https://agupubs.onlinelibrary.wiley.com/doi/abs/10.1029/2008WR007037

Mendoza, C., \& Zhou, D. (1992). Effects of porous bed on turbulent stream flow above bed. Journal of Hydraulic Engineering, 118(9), 1222-1240.

Nagaoka, H., \& Ohgaki, S. (1990). Mass transfer mechanism in a porous riverbed. Water Research, 24(4), 417-425.

Nikora, V. I., Goring, D., McEwan, I., \& Griffiths, G. (2001). Spatially averaged open-channel flow over rough bed. Journal of Hydraulic Engineering, 127(2), 123-133.

O'Connor, B. L., \& Harvey, J. W. (2008). Scaling hyporheic exchange and its influence on biogeochemical reactions in aquatic ecosystems. Water Resources Research, 44(12).

Orr, C. H., Clark, J. J., Wilcock, P. R., Finlay, J. C., \& Doyle, M. W. (2009). Comparison of morphological and biological control of exchange with transient storage zones in a field-scale flume. Journal of Geophysical Research: Biogeosciences, 114(G2). http://dx.doi.org/10.1029/2008JG000825

Packman, A. I., Salehin, M., \& Zaramella, M. (2004). Hyporheic Exchange with Gravel Beds: Basic Hydrodynamic Interactions and Bedform-Induced Advective Flows. Journal of Hydraulic Engineering, 130(7), 647-656. http://dx.doi.org/10.1061/(ASCE)0733-9429(2004)130:7(647)

Richardson, C. P., \& Parr, A. D. (1988). Modified Fickian model for solute uptake by runoff. Journal of environmental engineering, 114(4), 792-809.

Risken, H. (1996). Fokker-planck equation. In The Fokker-Planck Equation (pp. 63-95): Springer. 
Roche, K. R., Blois, G., Best, J. L., Christensen, K. T., Aubeneau, A. F., \& Packman, A. I. (2018). Turbulence Links Momentum and Solute Exchange in Coarse-Grained Streambeds. Water Resources Research, 54, 32253242. https://agupubs.onlinelibrary.wiley.com/doi/abs/10.1029/2017WR021992

Ruff, J., \& Gelhar, L. (1972). Turbulent shear flow in porous boundary. J. Engrg. Mech, 504(98), 975.

Schumer, R., Benson, D. A., Meerschaert, M. M., \& Baeumer, B. (2003). Fractal mobile/immobile solute transport. Water Resources Research, 39(10).

Sherman, T., Roche, K. R., Richter, D. H., Packman, A. I., \& Bolster, D. (2019). A Dual Domain Stochastic Lagrangian Model for Predicting Transport in Open Channels with Hyporheic Exchange. Advances in Water Resources. http://www.sciencedirect.com/science/article/pii/S0309170818305505

Singha, K., Day-Lewis, F. D., Johnson, T., \& Slater, L. D. (2015). Advances in interpretation of subsurface processes with time-lapse electrical imaging. Hydrological Processes, 29(6), 1549-1576. https://onlinelibrary.wiley.com/doi/abs/10.1002/hyp.10280

Sinha, S., Hardy, R. J., Blois, G., Best, J. L., \& Sambrook Smith, G. H. (2017). A numerical investigation into the importance of bed permeability on determining flow structures over river dunes. Water Resources Research, 53(4), 3067-3086. http://dx.doi.org/10.1002/2016WR019662

Taylor, G. (1954). The Dispersion of Matter in Turbulent Flow through a Pipe. Proceedings of the Royal Society of London. Series A, Mathematical and Physical and Engineering Sciences, 223(1155), 446-468.

Tennekes, H., \& Lumley, J. L. (1972). A first course in turbulence: MIT press.

Uijttewaal, W., Lehmann, D., \& Mazijk, A. v. (2001). Exchange Processes between a River and Its Groyne Fields: Model Experiments. Journal of Hydraulic Engineering, 127(11), 928-936. http://dx.doi.org/10.1061/(ASCE)0733-9429(2001)127:11(928)

Voermans, J. J., Ghisalberti, M., \& Ivey, G. N. (2017). The variation of flow and turbulence across the sedimentwater interface. Journal of Fluid Mechanics, 824, 413-437. https://www.cambridge.org/core/article/variation-of-flow-and-turbulence-across-the-sedimentwaterinterface/E4ADF6CD754ADDF9482C8EDF611B91C7

Voermans, J. J., Ghisalberti, M., \& Ivey Gregory, N. (2018). A Model for Mass Transport Across the SedimentWater Interface. Water Resources Research, O(0). https://doi.org/10.1002/2017WR022418

Vollmer, S., de los Santos Ramos, F., Daebel, H., \& Kühn, G. (2002). Micro scale exchange processes between surface and subsurface water. Journal of Hydrology, 269(1-2), 3-10. http://www.sciencedirect.com/science/article/pii/S0022169402001907

Ward, A. S., Gooseff, M. N., \& Singha, K. (2010). Imaging hyporheic zone solute transport using electrical resistivity. Hydrological Processes, 24(7), 948-953. https://onlinelibrary.wiley.com/doi/abs/10.1002/hyp.7672

Zagni, A. F., \& Smith, K. V. (1976). Channel flow over permeable beds of graded spheres. Journal of the Hydraulics Division, 102(2), 207-222.

Zarnetske, J. P., Haggerty, R., Wondzell, S. M., \& Baker, M. A. (2011). Dynamics of nitrate production and removal as a function of residence time in the hyporheic zone. Journal of Geophysical Research: Biogeosciences (2005--2012), 116(G1).

Zhang, Y., \& Meerschaert, M. M. (2011). Gaussian setting time for solute transport in fluvial systems. Water Resources Research, 47(8), n/a-n/a. http://dx.doi.org/10.1029/2010WR010102

Zhou, D., \& Mendoza, C. (1993). Flow through Porous Bed of Turbulent Stream. Journal of Engineering Mechanics, 119(2), 365-383. http://dx.doi.org/10.1061/(ASCE)0733-9399(1993)119:2(365)

Zumofen, G., \& Klafter, J. (1993). Scale-invariant motion in intermittent chaotic systems. Physical Review E, 47(2), 851. 
Table 1. Measured and calculated conditions, based on experiments from Roche et al. (2018).

\begin{tabular}{|c|c|c|c|}
\hline $\boldsymbol{R} \boldsymbol{H}$ & $\mathbf{4 2 , 0 0 0}$ & $\mathbf{2 1 , 0 0 0}$ & $\mathbf{1 1 , 0 0 0}$ \\
\hline $\boldsymbol{H}(\mathbf{m})$ & \multicolumn{3}{|c|}{0.123} \\
\hline $\boldsymbol{d}_{\boldsymbol{b}}(\mathbf{m})$ & \multicolumn{3}{|c|}{0.224} \\
\hline $\boldsymbol{Q}\left(\mathbf{L ~ s} \mathbf{- 1}^{-1}\right)$ & 8.8 & 4.4 & 2.2 \\
\hline$\overline{\boldsymbol{U}}_{\boldsymbol{s}}\left(\mathbf{m ~ s}^{-1}\right)$ & 0.340 & 0.174 & 0.088 \\
\hline $\boldsymbol{u}_{\boldsymbol{p}}\left(\times \mathbf{1 0}^{-\mathbf{2}} \mathbf{m ~ s}^{-1}\right)$ & 1.85 & 0.63 & 0.29 \\
\hline $\boldsymbol{K}_{\boldsymbol{p}, \exp }\left(\times \mathbf{1 0}^{-4} \mathbf{m}^{\mathbf{2}} \mathbf{~ s}^{-1}\right)$ & 0.34 & 0.20 & 0.15 \\
\hline
\end{tabular}


Table 2. Specific cases used for reach-scale simulations.

\begin{tabular}{|c|c|c|c|}
\hline Case & Fixed Conditions & Varying condition & Purpose \\
\hline $\mathbf{a}$ & $\begin{array}{l}\text { Enhanced interfacial } \\
\text { mixing profile } \\
d_{b}=1.0 \mathrm{~m} \\
\text { Measured hyporheic } u_{z}\end{array}$ & $\begin{array}{l}\text { 1. } R e=42,000 \\
\text { 2. } R e=21,000 \\
\text { 3. } R e=11,000\end{array}$ & $\begin{array}{l}\text { Compare hyporheic RTDs } \\
\text { across flow conditions } \\
\text { (independent of } L \text { ) }\end{array}$ \\
\hline b & $\begin{array}{l}L=50 \mathrm{~m}, 250 \mathrm{~m} \\
R e=42,000 \\
d_{b}=5.0 \mathrm{~m} \\
u_{z}(z<0)=0\end{array}$ & $\begin{array}{l}\text { 1. Enhanced } K_{z} \text { profile } \\
\text { 2. Uniform } K_{z} \text { profile }\end{array}$ & $\begin{array}{l}\text { Assess influence of } \\
\text { enhanced interfacial } \\
\text { mixing on BTCs }\end{array}$ \\
\hline c & $\begin{array}{l}L=250 \mathrm{~m} \\
R e=42,000,11,000 \\
d_{b}=5.0 \mathrm{~m} \\
\text { Enhanced } K_{z} \text { profile }\end{array}$ & $\begin{array}{l}\text { 1. } u_{z}(z<0)=0 \\
\text { 2. Measured hyporheic } u_{z}\end{array}$ & $\begin{array}{l}\text { Assess influence of } \\
\text { nonzero hyporheic } \\
\text { velocity on BTCs }\end{array}$ \\
\hline d & $\begin{array}{l}L=50 \mathrm{~m}, 500 \mathrm{~m} \\
R e=42,000 \\
d_{b}=5.0 \mathrm{~m} \\
\text { Enhanced } K_{z} \text { profile } \\
\text { Measured hyporheic } u_{z}\end{array}$ & $\begin{array}{l}\text { 1. } d_{b}=5.0 \mathrm{~m} \\
\text { 2. } d_{b}=0.5 \mathrm{~m}\end{array}$ & $\begin{array}{l}\text { Demonstrate dual controls } \\
\text { of } \tau_{a d v} \text { and } \tau_{b e d} \text { on BTCs }\end{array}$ \\
\hline e & $\begin{array}{l}R e=42,000 \\
\text { Enhanced } K_{z} \text { profile } \\
\text { Measured hyporheic } u_{z}\end{array}$ & $\begin{aligned} d_{b}= & 0.11,0.22,0.5 \\
& 1.0,2.0,5.0 \mathrm{~m}\end{aligned}$ & $\begin{array}{l}\text { Compare hyporheic RTDs } \\
\text { and mass recovery across } \\
\text { streambed depths } \\
\text { (independent of } L \text { ) }\end{array}$ \\
\hline
\end{tabular}


Table 3. Model fits of decay rate, $\alpha$ (both models), interfacial mixing rate, $K_{e}$ (enhanced interfacial mixing model only), and porewater dispersion, $K_{p}$, to experimental observations. Free parameters are marked with a superscript ${ }^{*}$. The objective fitting function result is reported as the sum of squared errors $(S S E)$. Additional parameters calculated from these simulations are also reported: average vertical mixing rate for the water column (Equation 3), $\bar{K}_{w c}$; average vertical mixing rate in the enhanced interfacial mixing layer $\bar{K}_{z \in\left(z_{e n, 0}\right)}$; depth of enhanced interfacial mixing layer, $z_{e n}$; Gaussian setting timescale, $\tau_{\text {bed }}$, based on enhanced interfacial mixing model; and timescale of advective longitudinal washout from the hyporheic zone, $\tau_{a d v}$, based on simulations with a 5-m streambed.

\begin{tabular}{|c|c|c|c|c|}
\hline $\boldsymbol{R e}$ & -- & 42,000 & 21,000 & 11,000 \\
\hline \multirow{2}{*}{$S S E$} & Monotonic & 1.35 & 3.30 & 1.03 \\
\hline & Enhanced & 0.10 & 0.18 & 0.29 \\
\hline \multirow{2}{*}{$\begin{array}{r}{ }^{*} \alpha \\
\left(\mathbf{m}^{-1}\right)\end{array}$} & Monotonic & 674 & 660 & 440 \\
\hline & Enhanced & 63 & 75 & 50 \\
\hline \multirow{2}{*}{$\begin{array}{c}\bar{K}_{w c} \\
\left(\times 10^{-4} \mathbf{m}^{2} \mathrm{~s}^{-1}\right)\end{array}$} & $\begin{array}{c}\text { Monotonic, } \\
\text { Uniform }\end{array}$ & 5.22 & 2.80 & 1.43 \\
\hline & Enhanced & 7.86 & 5.65 & 1.70 \\
\hline \multirow{2}{*}{$\begin{array}{c}K_{z=0} \\
\left(\times 10^{-4} \mathrm{~m}^{2} \mathrm{~s}^{-1}\right)\end{array}$} & Monotonic, $K_{z}(0)$ & 1.15 & 0.71 & 0.39 \\
\hline & Enhanced, ${ }^{*} K_{e}$ & 13.29 & 11.34 & 1.74 \\
\hline \multirow{2}{*}{$\begin{array}{c}{ }^{*} K_{p} \\
\left(\times 10^{-4} \mathbf{m}^{2} \mathbf{s}^{-1}\right) \\
\end{array}$} & Monotonic & 0.34 & 0.06 & 0.12 \\
\hline & Enhanced & 0.15 & 0.05 & 0.03 \\
\hline \multirow{2}{*}{$\begin{array}{c}\bar{K}_{z \in\left(z_{e n, 0)}\right.} \\
\left(\times \mathbf{1 0}^{-4} \mathbf{m}^{2} \mathbf{s}^{-1}\right) \\
\end{array}$} & Monotonic & 0.64 & 0.26 & 0.20 \\
\hline & Enhanced & 3.15 & 2.64 & 0.41 \\
\hline \multirow{2}{*}{$\begin{array}{c}z_{e n} \\
\left(\times 10^{-2} \mathbf{m}\right) \\
\end{array}$} & Monotonic & -1.1 & -1.1 & -1.5 \\
\hline & Enhanced & -7.3 & -6.3 & -8.7 \\
\hline \multirow{3}{*}{$\begin{array}{c}\tau_{b e d}=d_{b}^{2} / \bar{K}_{H Z} \\
\left(\times 10^{4} \mathrm{~s}\right)\end{array}$} & $d_{b}=0.5 \mathrm{~m}$ & 0.4 & 0.7 & 2.4 \\
\hline & $d_{b}=1.0 \mathrm{~m}$ & 2.6 & 4.6 & 14.9 \\
\hline & $d_{b}=5.0 \mathrm{~m}$ & 126 & 290 & 610 \\
\hline \multirow{2}{*}{$\begin{array}{c}\tau_{a d v}=L / \bar{U}_{H Z} \\
\left(\times 10^{4} \mathrm{~s}\right)\end{array}$} & $L=50 \mathrm{~m}$ & 0.3 & 0.6 & 1.8 \\
\hline & $L=250 \mathrm{~m}$ & 1.2 & 3.1 & 8.9 \\
\hline
\end{tabular}


Table 4. CTRW model fits to simulations at $R e$ 42,000. Mean water column velocity $\left(\bar{U}_{S}\right)$, longitudinal dispersion $(D)$, and immobilization rate $(\Lambda)$ are calculated from simulations. The RTD power-law slope $(\beta)$ is determined from theoretical arguments (see Section 2.3.1). The modified CTRW model, which accounts for enhanced interfacial mixing, also contains parameters representing the mean residence time in the enhanced interfacial mixing layer $\left(\mu_{e n}\right.$, determined from simulations) and the rate of mass transfer from the enhanced mixing layer to the deeper hyporheic sublayer $\left(\Lambda_{e n}\right)$. The model with enhanced interfacial mixing contains one free parameter, $\Lambda_{e n}$.

\begin{tabular}{|c|c|c|}
\hline & Uniform Mixing & $\begin{array}{c}\text { Enhanced } \\
\text { Interfacial Mixing }\end{array}$ \\
\hline $\boldsymbol{U}_{\boldsymbol{\Psi}}\left(\mathbf{m ~ s}^{\mathbf{- 1}}\right)$ & 0.34 & 0.34 \\
\hline $\boldsymbol{D}_{\boldsymbol{\Psi}}\left(\mathbf{m}^{\mathbf{2}} \mathbf{~ s}^{\mathbf{1}}\right)$ & 0.036 & 0.036 \\
\hline $\boldsymbol{\Lambda}\left(\mathbf{s}^{-\mathbf{1}}\right)$ & 0.04 & 0.13 \\
\hline $\boldsymbol{c}_{\boldsymbol{\beta}}$ & 1 & 1 \\
\hline $\boldsymbol{\beta}$ & 0.5 & 0.5 \\
\hline $\boldsymbol{\mu}_{\boldsymbol{e n}}(\mathbf{s})$ & -- & 4.44 \\
\hline $\boldsymbol{\Lambda}_{\boldsymbol{e n}}\left(\mathbf{s}^{\mathbf{- 1}}\right)$ & -- & 0.02 \\
\hline
\end{tabular}

\section{Figure captions}

Figure 1. Left: Conceptual profile of average longitudinal velocity $u_{x}(z)$. Velocities were measured from experiments in Roche et al. (2018). Porewater velocity, $u_{p}$, is reached at depths in the streambed where flows are not altered by surface-subsurface flow coupling. Right: Hypothesized profiles of vertical mixing, $K_{z}(z)$. Profiles decay exponentially below the SWI $(z$ $<0) . K_{e}$ is the mixing rate at the SWI for profiles with enhanced mixing, and $K_{p}$ is the vertical mixing rate in the porewater.

Figure 2. Observed and simulated steady-state concentration profiles for surface (a-c) and subsurface (d-f) tracer injections. Simulations parameterized with the enhanced interfacial mixing profile outperformed simulations with the monotonic decrease mixing profile when compared to experiments. Colored horizontal lines indicate injection elevation.

Figure 3. Residence time distributions for the different modeled zones in the reach-scale simulations (colored hues) and the entire hyporheic zone (black line). Results are for simulations with a 1-m streambed, using the enhanced interfacial mixing profile. The zone between $z=-0.08$ $\mathrm{m}$ and the SWI (light hues) is approximately exponentially distributed for $R e$ 21,000 and $R e$ 42,000 simulations. The same zone shows slight tailing behavior for $R e 11,000$, which indicates that it is not well mixed at this flow condition. The RTDs for the deep hyporheic sublayer, $z \leq-$ $0.08 \mathrm{~m}$, follow a $\sim t^{-1 / 2}$ power-law, due to uniform vertical mixing over the entire zone (dark hues). All RTDs are tempered at late times at $\sim \tau_{\text {bed }}$. 
Figure 4. BTCs for simulations at Re 42,000 using a uniform hyporheic mixing profile (black dots), and the enhanced interfacial mixing profile (blue dots). Streambed depth is $5 \mathrm{~m}$, and streamwise hyporheic velocities are set to zero. The uniform mixing case is well described by a CTRW model with a power law wait-time distribution (black lines), and the enhanced mixing case is well described by a CTRW model with a hyporheic zone RTD that includes a well-mixed interfacial layer (blue lines).

Figure 5. BTCs for simulations using the enhanced interfacial mixing profile, with zero hyporheic velocity (black) and measured hyporheic velocity (colors). Simulations using observed hyporheic velocities exhibit steeper power-law slopes than the $\sim t^{-1 / 2}$ prediction, as well as rapid exponential tempering at $\tau_{a d v}$. Streambed depth was $5 \mathrm{~m}$ for both simulations. (a) $R e$ 42,000; (b) Re 11,000.

Figure 6. BTCs for simulations with $\operatorname{Re} 42,000$ and different streambed depths. Both simulations were parameterized with observed hyporheic velocities and the enhanced interfacial mixing profile. (a) 50-m reach; (b) 500-m reach. BTCs with $\tau_{a d v} / \tau_{b e d}<\sim 2$ show steep exponential tempering, while BTCs with $\tau_{a d v} / \tau_{b e d}>\sim 2$ show broad exponential tempering. $\tau_{a d v} / \tau_{b e d}<1$ for all simulations except the $0.5 \mathrm{~m}$ streambed simulation at $L=250 \mathrm{~m}\left(\tau_{a d v} / \tau_{b e d} \approx 3\right)$. $\tau_{\text {bed }}$ is greater than the maximum plotted time for both simulations in (a), and for the $5 \mathrm{~m}$ streambed simulation in (b). Values of $\tau_{a d v}$ are approximately equal for both simulations. Note the change in $x$ - and $y$-axis scales.

Figure 7. (a) Streambed RTDs for $R e$ 42,000 and varying flow depths. The RTDs are characterized by three features: (i) exponential tailing at short-to-intermediate times $\left(t<\sim 5 \times 10^{2}\right.$ s); (ii) $\sim t^{-1 / 2}$ power-law tailing, over an interval that varies with streambed depth; and (iii) exponential tempering after $\sim \tau_{\text {bed }}$. Power-law tailing disappears for cases with shallow streambeds, and the streambed RTD is approximately exponential. (b) Mass recovery, defined as the fraction of total tracer particles exiting the reach through the water column, varies with streambed depth and reach length. Recovery eventually approaches a value predicted by the fraction of total discharge in the water column (dotted lines). 
Figure 1
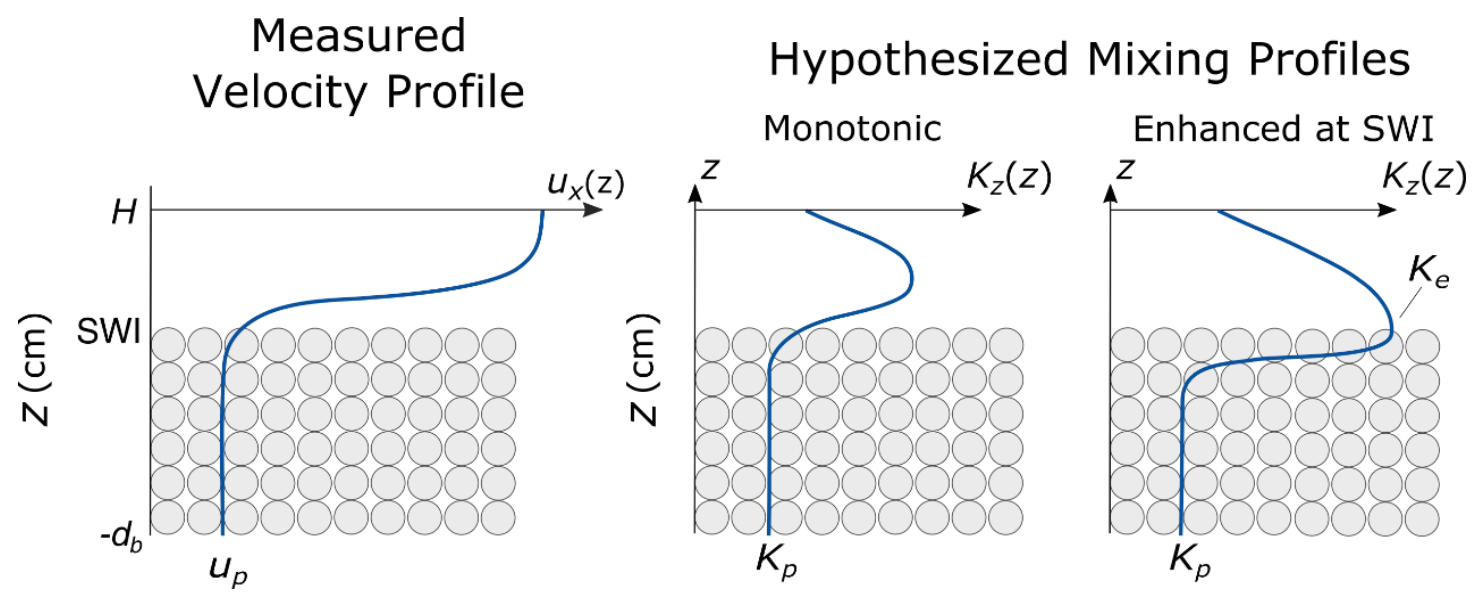
Figure 2
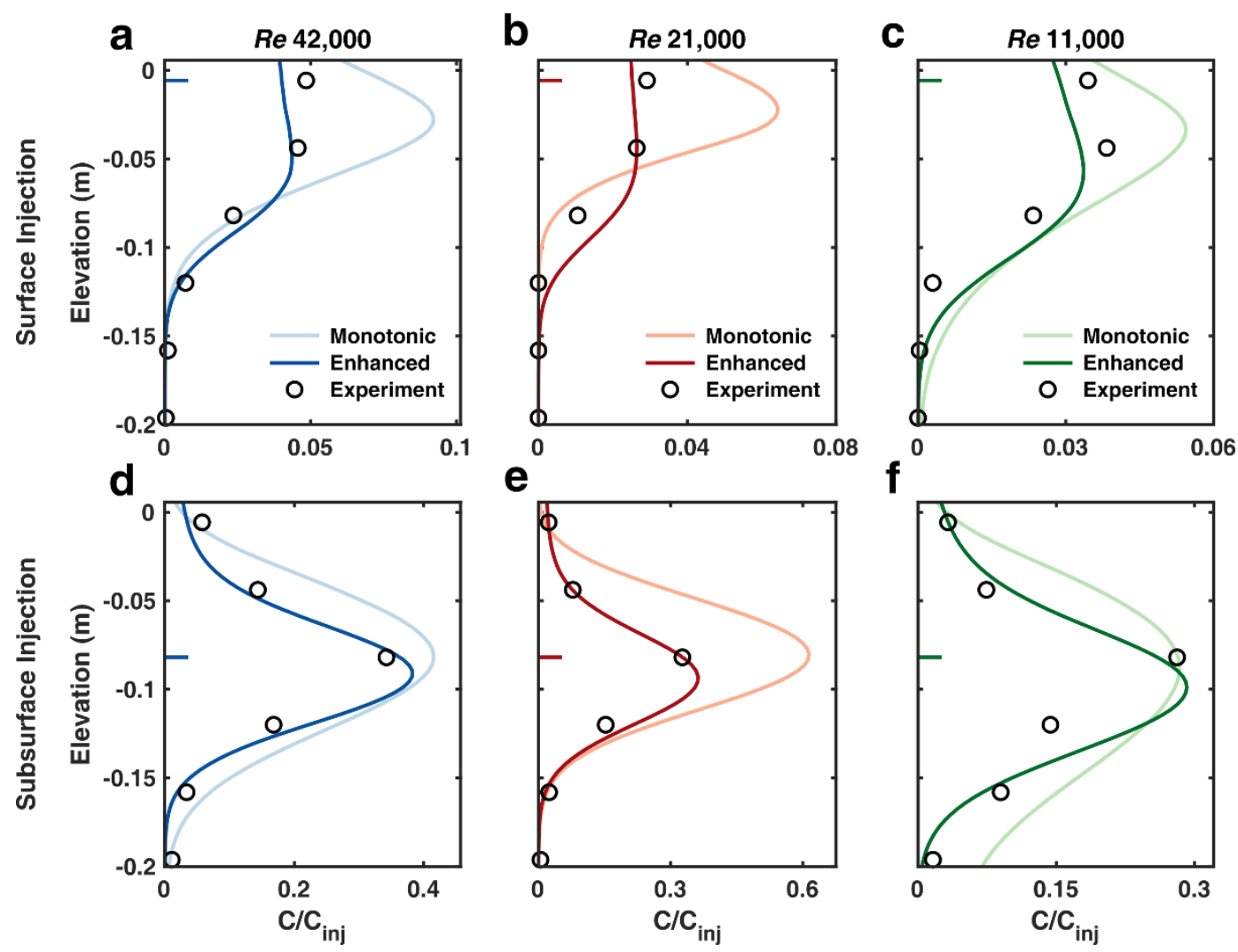
Figure 3
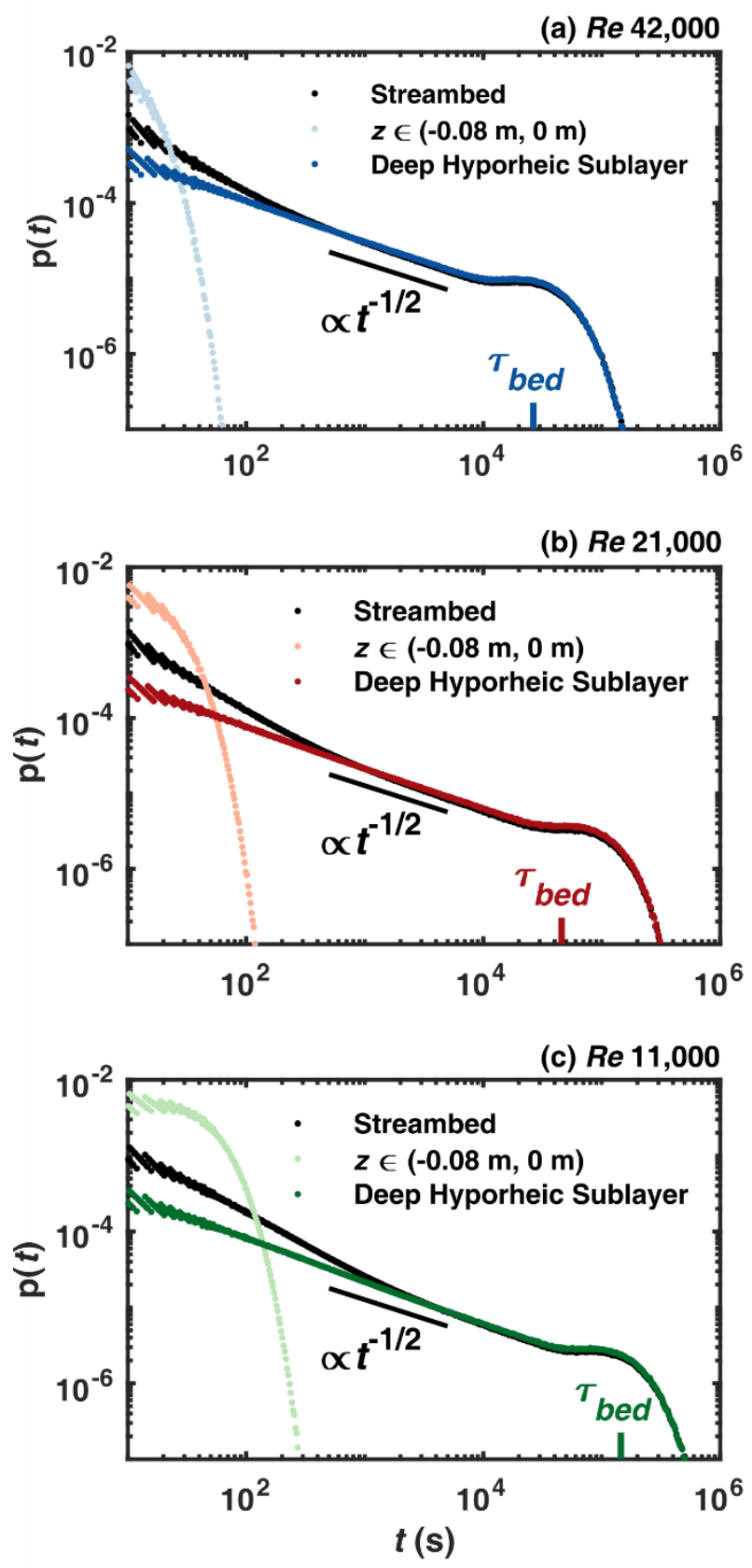
Figure 4

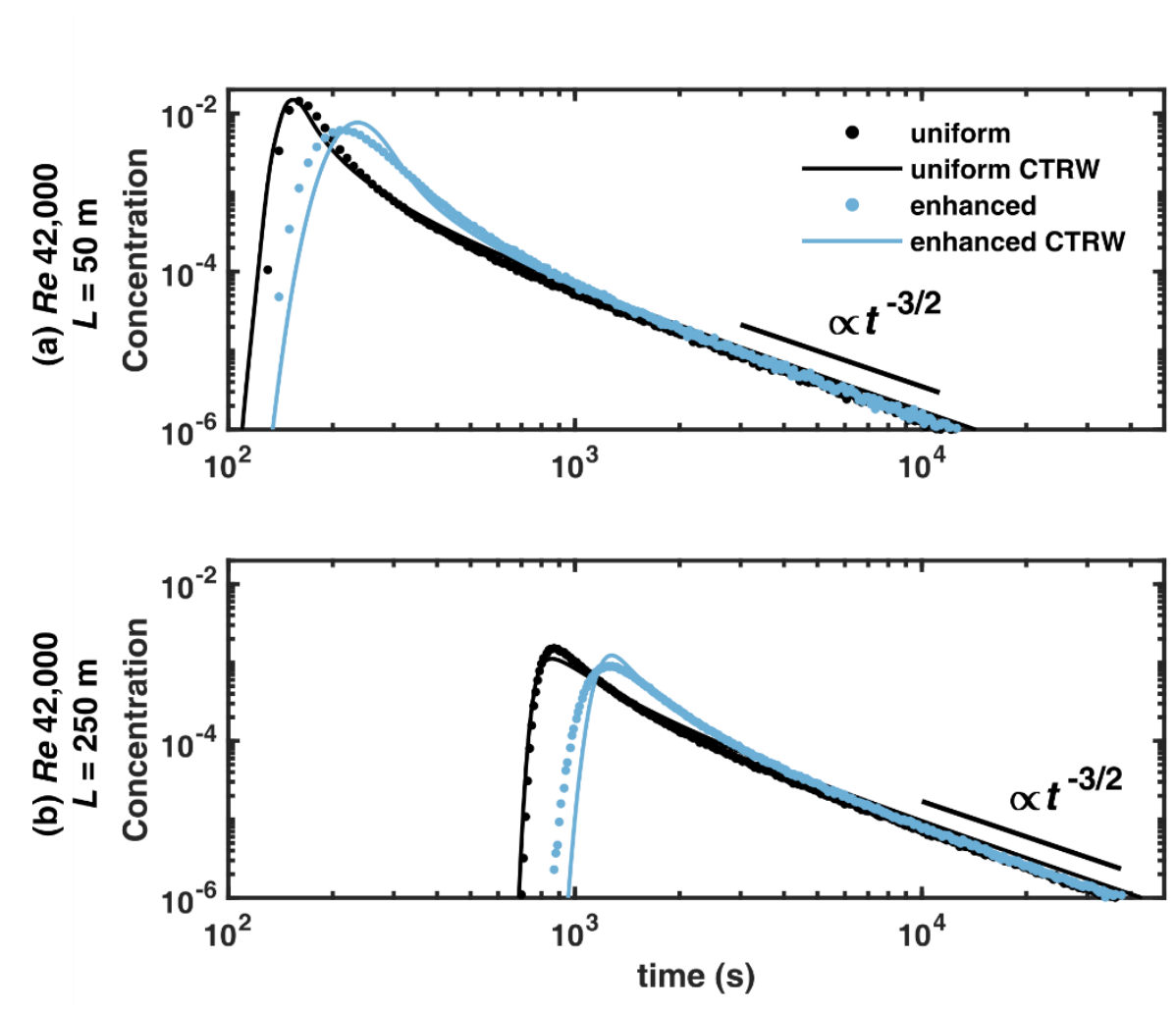


Figure 5
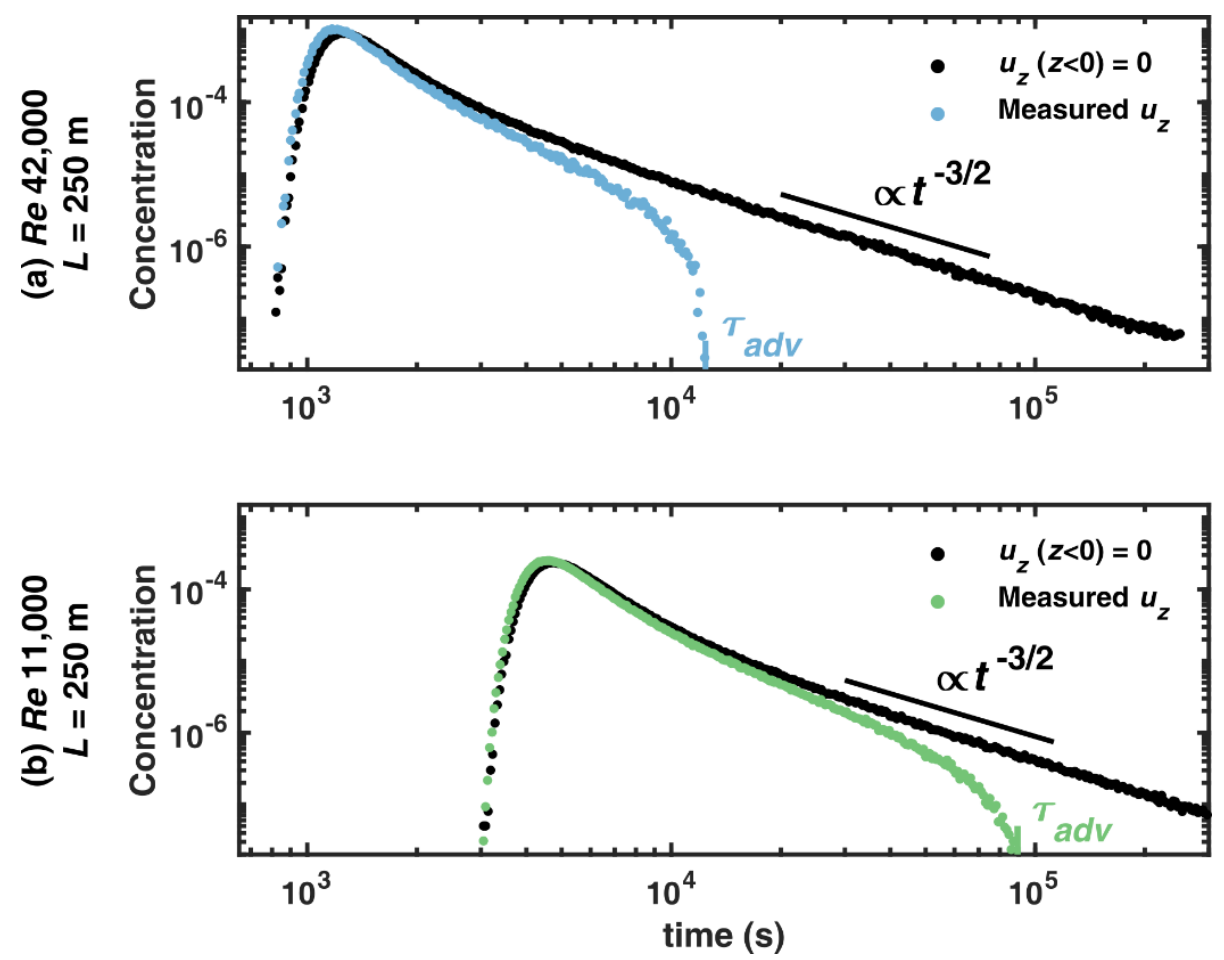
Figure 6
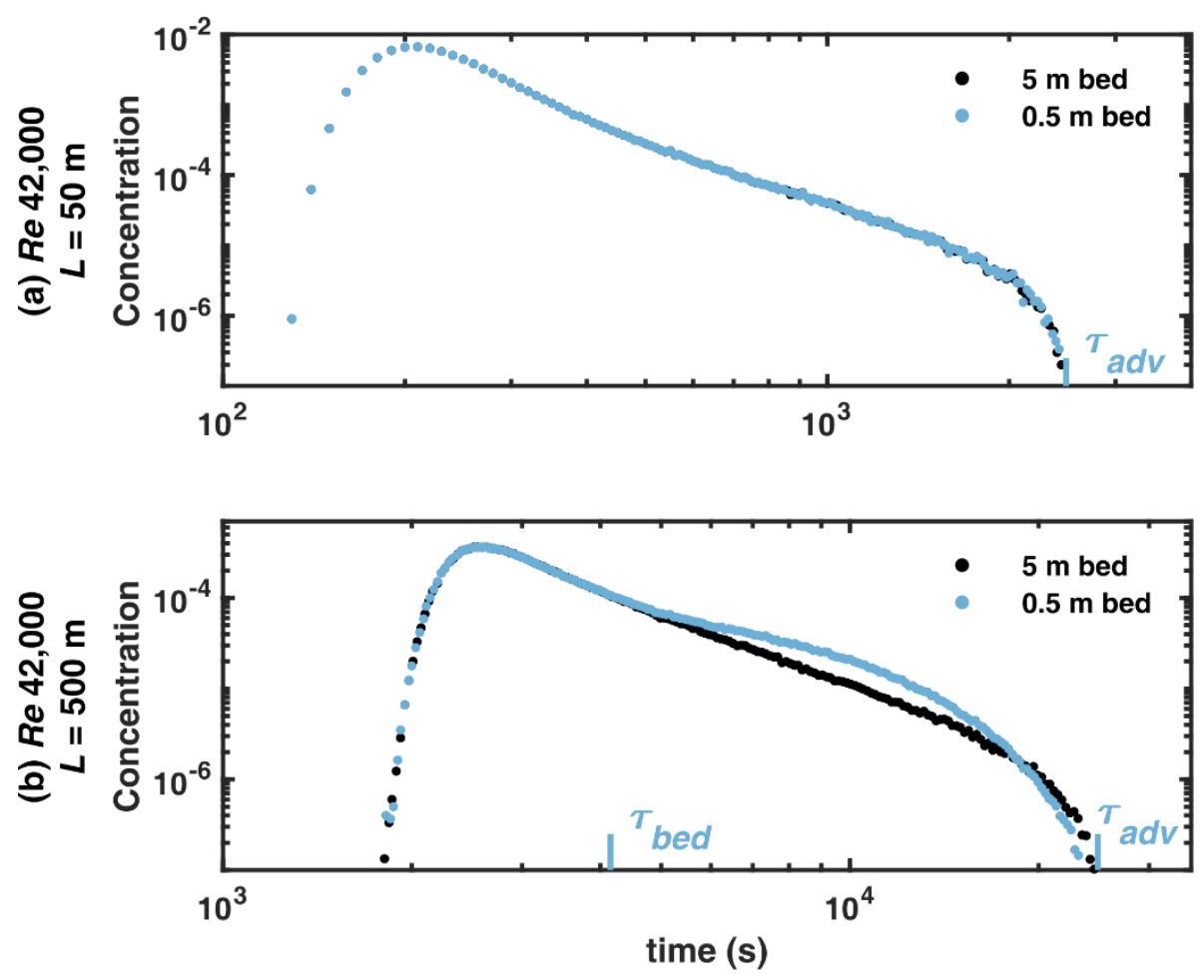
Figure 7
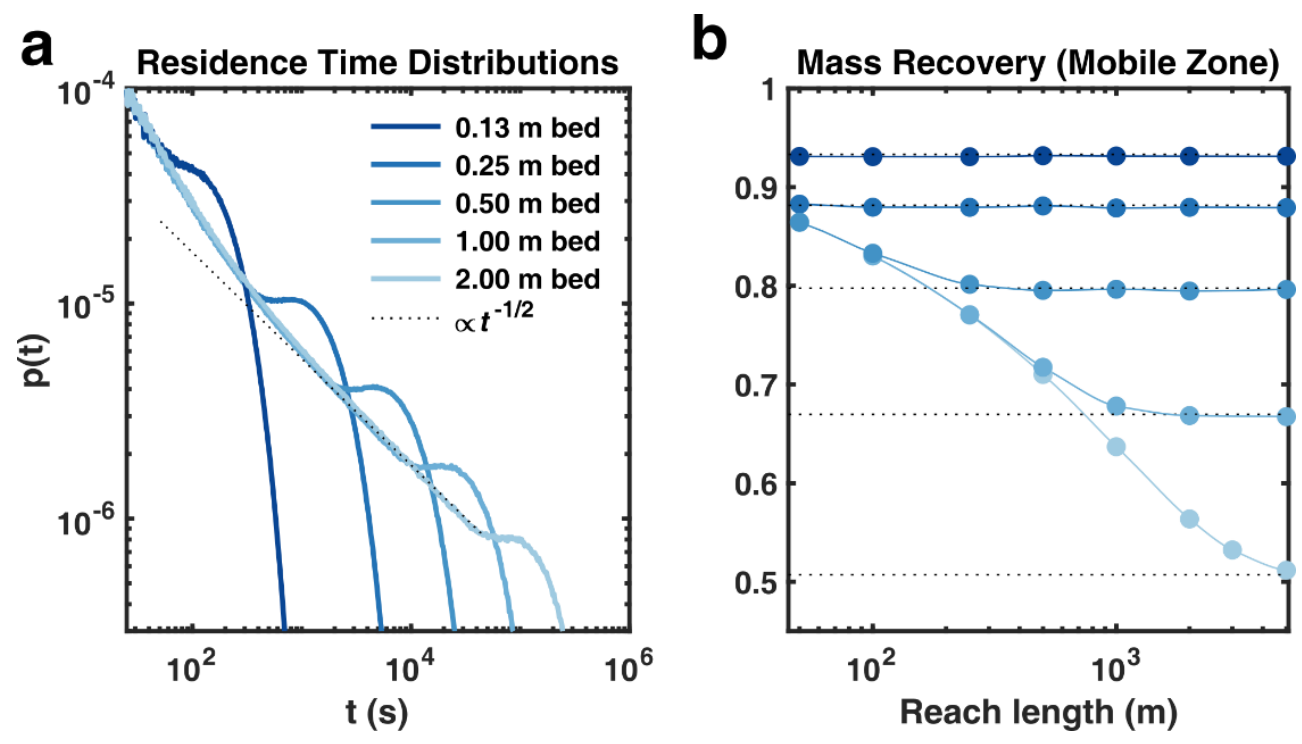